\title{
Factors affecting thermal stability of collagen from the aspects of extraction, processing and modification
}

\author{
Xiaoxia Zhang ${ }^{1,2}$, Songcheng $X u^{1,2}$, Lirui Shen ${ }^{1,2}$ and Guoying $\mathrm{Li}^{1,2^{*}}$ (D)
}

\begin{abstract}
Collagen, as a thermal-sensitive protein, is the most abundant structural protein in animals. Native collagen has been widely applied in various fields due to its specific physicochemical and biological properties. The beneficial properties would disappear with the collapse of the unique triple helical structure during heating. Understanding thermal stability of collagen is of great significance for practical applications. Previous studies have shown the thermal stability would be affected by the different sources, extraction methods, solvent systems in vitro and modified methods. Accordingly, the factors affecting thermal stability of collagen are discussed in detail in this review.
\end{abstract}

Keywords: Collagen, Thermal stability, Extraction methods, Solvent systems, Modification methods

\section{Introduction}

Leather manufactured from animal skins is extensively used for industrial commodity. The quality of leather is established on the stability of collagen which is an important structural protein in animal skins and accounts for $80-85 \%$ in dermal proteins [1]. Collagen as the most abundant protein in many tissues is widely presented not only in the skins, bones, tendons, ligaments, cartilage and blood vessels of vertebrates but also in the corneum of invertebrates and some simple multicellular organisms [2-4]. Today, 29 members of collagen have been found and could be classified as fibril-forming collagens (I, II, III, V, XI, XXIV and XXVII) and non-fibril-forming collagens [5].

The feature of collagen is defined as containing at least one helix domain, namely triple helix. Three parallel left-hand polypeptide chains ( $\alpha$ chains) with polyproline II-type (PPII) conformation coil about each other to form a right-handed triple helix (Fig. 1a). Collagen could be a homotrimer of three identical $\alpha$ chains as well as a

\footnotetext{
*Correspondence: liguoyings@163.com

'National Engineering Laboratory for Clean Technology of Leather Manufacture, Sichuan University, Chengdu 610065, PR China

${ }^{2}$ Key Laboratory of Leather Chemistry and Engineering (Ministry of Education), Sichuan University, Chengdu 610065, PR China
}

heterotrimer of two or three different $\alpha$ chains. The amino acid sequence shows every third residue is glycine (Gly), which results in a Gly-X-Y repeating sequence where $\mathrm{X}$ is often proline (Pro) and $\mathrm{Y}$ is often hydroxyproline (Hyp) [6]. Type I collagen is the most major and abundant member in the collagen family. At present, the knowledge of collagen mostly comes from the studies of type I collagen [4]. As a heterotrimer of two different $\alpha$ chains $\left(\left[\alpha_{1}(\mathrm{I})\right]_{2} \alpha_{2}(\mathrm{I})\right)$, Type I collagen contains $96 \%$ triple-helical domain and less non-helical domain, as shown in Fig. 2b. Non-helical domain with loose folded conformation is attributed to the absence of the Gly-X-Y repeating consequence in the $\mathrm{N}$ - and $\mathrm{C}$-telopeptides $[9$, 10]. The hydrogen bonds, including $\mathrm{N}-\mathrm{H}$ (Gly) $\ldots \mathrm{O}=\mathrm{C}$ (X) hydrogen bond, $\mathrm{O}-\mathrm{H}$ (Hyp in $\mathrm{Y}$ ) ... $\mathrm{O}=\mathrm{C}$ (peptide backbone) hydrogen bond and water mediated hydrogen bond, among $\alpha$ chains stabilize collagen triple helix (Fig. 1b) [7]. Other intermolecular non-covalent bonds such as van der Waals forces, electrostatic attractions and hydrophobic bonds also play an important role in stabilizing collagen [8]. In vivo, the biosynthetic route of type I collagen is shown in Fig. 2. N- and C-propeptides of type I procollagen are cleaved by corresponding 
a

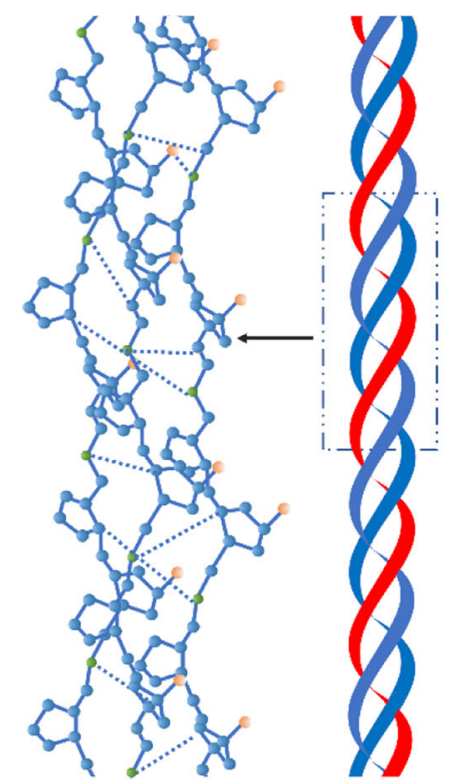

b

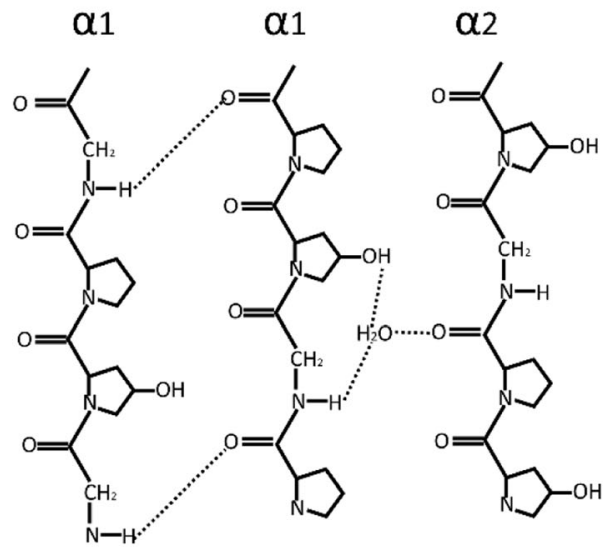

Fig. 1 (a) The triple helix of type I collagen [6]. (b) Hydrogen bonds of the collagen model [7]

proteases to transform into tropocollagen. The tropocollagens laterally and longitudinally aggregate to microfibers by self-assembly. The microfibers are further crosslinked and eventually form macroscopic fibers and network which could be observed in tissues. As weaving into a three-dimensional architecture, the collagen fibers contribute a desirable mechanical function to skin [11].

Triple helix establishes excellent characteristics for collagen, such as fiber-forming property, biocompatibility and bioactivity, which make collagen widely used in leather industry, tissue engineering [12], pharmaceuticals [13], foods [14] and cosmetics [15]. Native collagen has been molded into different forms to adequate to the specific demands: fibers for skin in leather industry, members for sausage casing in foods, aqueous solution for a standard raw material in cosmetic formulations and gels, pellets, nanoparticles, scaffolds, sponges for biomedicines [16].

Collagen is premised on maintaining the stability of the triple helix for all biological applications. The hydrogen bonds would be easily destroyed after absorbing excessive heat, which lead to the conformation transition of collagen. The thermal denaturation would take place above a certain temperature. In general, the thermal stability of collagen is expressed by denaturation temperature (Td) as well as shrinkage temperature (Ts). The higher Td or Ts, the better thermal stability [17]. Comparing with native collagen, the thermal denatured products of native collagen (gelatin and collagen hydrolysate) exhibit quite another properties such as relative lower molecular weight, absence of conformation translation, loss of ability of fibril formation, faintly promoting effect on the adsorption and growth of keratinized cells $[15,18]$. The occurrence of thermal denaturation should be prevented during processing, storage and application. The thermal stability of collagen has always been an issue of concern. This review mainly discusses the effects of extraction methods, sources, solvent systems and modification methods on thermal stability of type I collagen.

\section{The effect of extraction methods on thermal stability}

As an insoluble macromolecular structure in vivo, collagen has usually been extracted into solution in order to be further used. Native collagen with intact triple helix would be obtained by the following brief processes: pretreating for removing the non-collagenous substances, extracting and purifying at a low temperature. The effect of the extraction methods which are commonly used or are new on thermal stability of collagen are summarized in this review.

\subsection{Acid extraction and enzyme extraction}

Acid and enzyme have been wildly applied to the extraction of native collagen. Dilute acid could destroy the intermolecular salt bonds and Schiff bases, enhancing the repulsive charges on the triple helix to swell collagen fibers. Collagen extracted in acid solution still retains triple helix with amino telopeptide. Acetic acid, citric acid, lactic acid and hydrochloric acid could be used to extract collagen from tissues. Acetic acid is the best ideal acid solvent due to the high yield of extraction and bacteriostatic action $[19,20]$. Acid-soluble collagen (ASC) is 


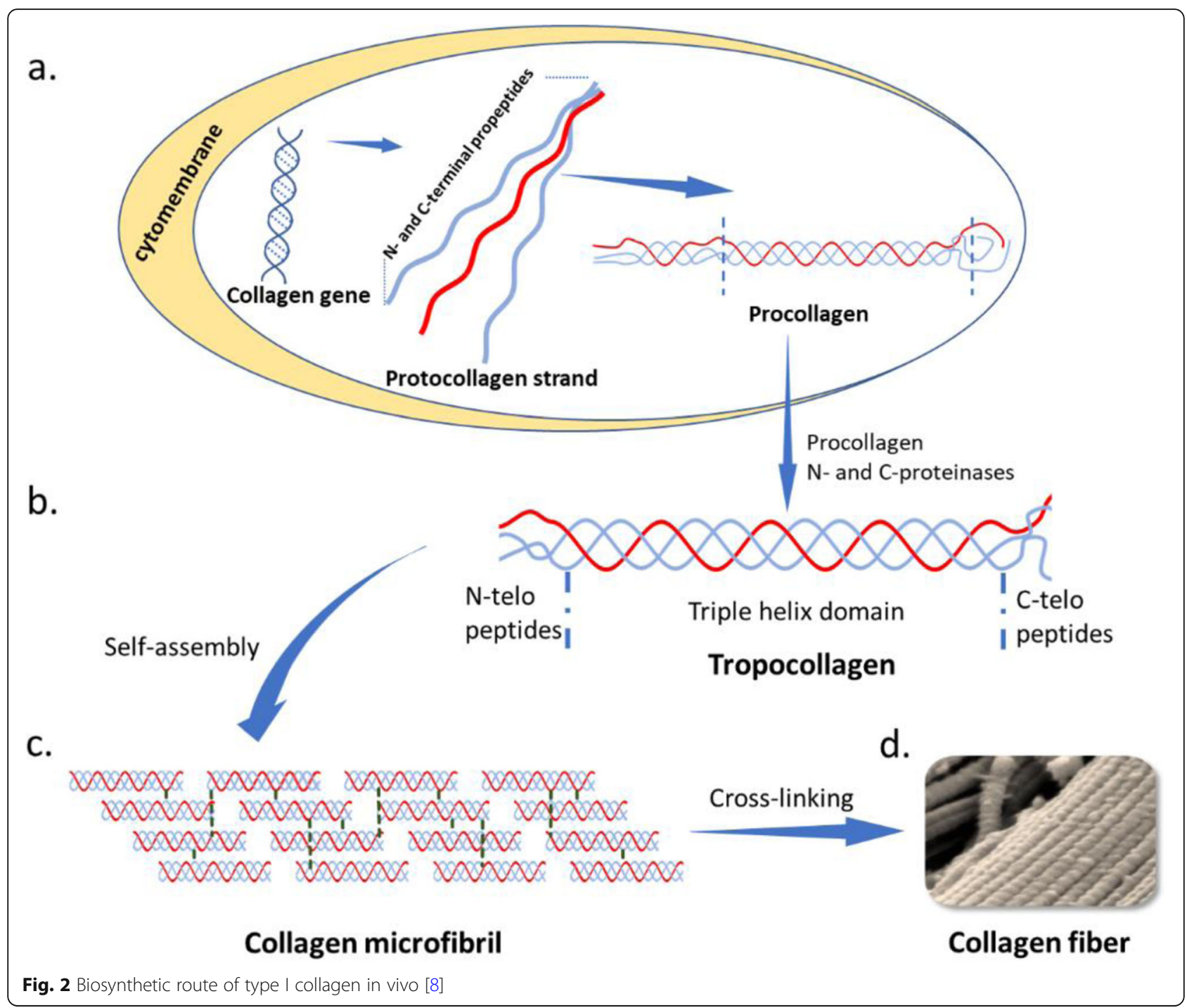

commonly extracted using $0.5 \mathrm{M}$ acetic acid solution. Enzyme could break the highly crosslinked bonds that cannot be broken by dilute acid in the telopeptide nonhelical domains of collagen to obtain the atelocollagen. Pepsin-soluble collagen (PSC), which is generally obtained using $0.5 \mathrm{M}$ acetic acid solution containing pepsin, has intact triple helix and shows low antigenicity thanks to the removal of telopeptides [21, 22]. The comparison of physicochemical properties between ASC and PSC has been studied by many researchers. The difference in denaturation temperature $(\Delta \mathrm{Td})$ between ASC and PSC was more than $1^{\circ} \mathrm{C}$ in some literatures, as listed in Table 1. Similar thermal stability shown between ASC and PSC has also been reported: ASC $\left(35.2^{\circ} \mathrm{C}\right)$ and $\operatorname{PSC}\left(34.5^{\circ} \mathrm{C}\right)$ of Nile tilapia skin [30], ASC $\left(41.58^{\circ} \mathrm{C}\right)$ and PSC $\left(41.01^{\circ} \mathrm{C}\right)$ of Spotted golden goatfish scale [31], ASC $\left(32.1^{\circ} \mathrm{C}\right)$ and PSC $\left(31.6^{\circ} \mathrm{C}\right)$ of Largefin longbarbel catfish skin [32], ASC $\left(16.1^{\circ} \mathrm{C}\right)$ and PSC $\left(15.7^{\circ} \mathrm{C}\right)$ of Deep-Sea Redfish skin [33],
ASC $\left(31.5^{\circ} \mathrm{C}\right)$ and PSC $\left(31.5^{\circ} \mathrm{C}\right)$ of Frog skin [34], ASC $\left(26.6^{\circ} \mathrm{C}\right)$ and PSC $\left(26.7^{\circ} \mathrm{C}\right)$ of Flatfish skin [35], ASC $\left(34.23^{\circ} \mathrm{C}\right)$ and PSC $\left(34.37^{\circ} \mathrm{C}\right)$ of Blacktip shark skin [36], $\operatorname{ASC}\left(39.3^{\circ} \mathrm{C}\right)$ and $\operatorname{PSC}\left(39.6^{\circ} \mathrm{C}\right)$ of Striped catfish skin [37].

The effect of those two methods on the thermal stability would be distinct owing to the different collagen sources, sample states and determination methods, as reported by Portier et al. [26] and Kozlowska et al. [38]. $\triangle \mathrm{Td}$ between ASC and PSC extracted from Black drum skin was $1.6^{\circ} \mathrm{C}$, whilst $\Delta \mathrm{Td}$ between ASC and PSC of Sheepshead skin was merely $0.3^{\circ} \mathrm{C}$ [26]. Td of ASC was $1.5^{\circ} \mathrm{C}$ higher than that of PSC determined by viscosity measurement but was $4.7^{\circ} \mathrm{C}$ lower than that of PSC in the form of film determined by differential scanning calorimetry (DSC) [38]. However, the intra- and intermolecular crosslinks in ASC-s was evidently richer than that in PSC-s. Additionally, ASC-s after the removal of telopeptides using the specific enzyme exhibited a 
Table 1 The difference in denaturation temperature/ $\Delta \mathrm{Td}>1{ }^{\circ} \mathrm{C}$ between ASC and PSC

\begin{tabular}{|c|c|c|c|c|c|}
\hline \multirow[t]{2}{*}{ Sources of collagen } & \multicolumn{2}{|c|}{$\operatorname{Td}\left({ }^{\circ} \mathrm{C}\right)$} & \multirow{2}{*}{$\begin{array}{l}\Delta \mathrm{Td} \\
\left({ }^{\circ} \mathrm{C}\right)\end{array}$} & \multirow{2}{*}{$\begin{array}{l}\text { Determination } \\
\text { methods of } \\
\text { Td. }\end{array}$} & \multirow[t]{2}{*}{ Reference } \\
\hline & ASC & PSC & & & \\
\hline Skin wastes of marine eel fish ${ }^{c}$ & 39 & 35 & $4^{a}$ & Viscometer & [23] \\
\hline Skulls of skipjack tuna ${ }^{c}$ & 17.8 & 16.6 & $1.2^{\mathrm{a}}$ & Viscometer & [24] \\
\hline Spines of skipjack tuna ${ }^{c}$ & 17.6 & 16.5 & $1.1^{\mathrm{a}}$ & Viscometer & [24] \\
\hline Bone of Spanish mackerel $^{c}$ & 18.02 & 16.85 & $1.17^{\mathrm{a}}$ & Viscometer & [25] \\
\hline Skin of black drum ${ }^{c}$ & 34.2 & 35.8 & $-1.6^{b}$ & Viscometer & [26] \\
\hline Loach skin ${ }^{c}$ & 36.03 & 33.61 & $2.42^{\mathrm{a}}$ & $C D$ & [27] \\
\hline Ovine bones ${ }^{c}$ & 42.31 & 38.91 & $3.4^{\mathrm{a}}$ & DSC & [28] \\
\hline Skin of grass carp ${ }^{d}$ & 69.04 & 62.2 & $6.84^{\mathrm{a}}$ & DSC & [29] \\
\hline
\end{tabular}

$C D$ Circular dichroism measurements, DSC Differential scanning calorimetry

${ }^{a} \mathrm{Td}$ of ASC is higher than that of PSC

${ }^{\mathrm{b}} \mathrm{Td}$ of PSC is higher than that of ASC

${ }^{c}$ Collagen solution

dLyophilized collagen

relative lower rate of fiber formation and a weaker collagen gel strength [39-41]. The telopeptides rich in hydrophobic residues are helpful for inter-microfibrillar interaction [42]. Accordingly, telopeptides might make a contribution to the thermal stability of collagen after fiber formation.

\subsection{Alkali extraction}

Back in early 20th century, several researchers investigated the effect of mild alkaline treatment on collagen, because liming is an essential process in the conversion of skins to leathers. Bowes et al. [43] suggested the hydrolysis of amide groups was the main reaction with a little breakage of some peptides when insoluble collagen was treated with alkali at $\mathrm{pH}$ 13.0. Courts [44] further proved the progressive hydrolysis of labile peptide bonds occurred in alkaline pretreatment of insoluble collagen. People focused on remaining collagen insoluble during alkaline treatment by keeping the $\mathrm{pH}$ value below 13 or using swelling restrainers [45]. Little work was described about the fraction soluble in alkali until 1971 by Kemp et al. [46]. A fraction of high molecular weight was isolated from cow bone ossein with $5 \%(\mathrm{w} / \mathrm{v}) \mathrm{NaOH}$ and $0.1 \mathrm{M} \mathrm{NaCl}$. The resulting material merited the description of 'collagen' owing to high content of the characteristic helix observed by optical-rotation studies. The Td values of the alkaline-soluble collagen was about $4^{\circ} \mathrm{C}$ lower than that of ASC extracted from cow skin [46]. Type I collagen was successfully extracted from bovine skin by Hattori et al. [47] using 3\% hydroxide and 1.9\% monomethylamine at $4^{\circ} \mathrm{C}$ for $1 \mathrm{~d}$. The thermal stability of the alkaline-soluble collagen $\left(38.0^{\circ} \mathrm{C}\right)$ was lower than that of ASC $\left(40.4^{\circ} \mathrm{C}\right)$. Similar results were reported by others $[48,49]$. Td of the alkaline-soluble collagen was $5^{\circ} \mathrm{C}$ lower than that of ASC-s and PSC-s extracted from shark skin [48]. The thermal stability of the alkaline- soluble collagen was lower than that of PSC extracted from pig skin and the $\mathrm{Td}$ values were 34.5 and $37^{\circ} \mathrm{C}$ respectively [49].

Alkali dissolved collagen through removing the telopeptides involved in crosslinkage of the molecules and could lead to the deamination of Asn and Gln into Asp and Glu. For the loss of telopeptides and the generation of the stronger electrostatic repulsion of Asp and Glu, the native collagen extracted with alkali has slightly less thermal stability comparing with ASC-s and PSC-s.

\subsection{Ultrasonic assisted and microwave assisted extraction}

Ultrasonic irradiation, as a safe, reliable, reproducible and environmentally friendly technology, is widely used to demonstrate physicochemical properties in lowintensity and promote emulsification, cell destruction and chemical reactions in high-intensity [50]. Cavitation as the most usual property of ultrasonic produces intense physical forces to provide sufficient energy for an extraction process [51]. Akram et al. [52] extracted acidsoluble type II collagen from chicken sternal cartilage using ultrasonic assist $(950 \mathrm{~W}, 20-25 \mathrm{kHz}$, amplitude

10 for $24 \mathrm{~min})$. $\mathrm{Td}$ of the collagen was $5^{\circ} \mathrm{C}$ higher than that of the un-ultrasonic treated collagen. $\mathrm{Qu}$ et al. [53] extracted pepsin-soluble type I collagen from bovine hide via ultrasonic assist in the optimal condition $(20 \mathrm{kHz}$ and $90 \mathrm{~W}$ for $20 \mathrm{~min})$. Td of the collagen $\left(40.09^{\circ} \mathrm{C}\right)$ was similar to that of PSC $\left(39.87^{\circ} \mathrm{C}\right)$. With the help of ultrasonic, native collagen has been successfully obtained in a short time with high yield [54-57]. It should be noted that an evident degradation of collagen would take place after ultrasonic treatment for a longer duration time or under a higher degree of amplitude, as reported by Kim HK et al. [58, 59]. The effects of different ultrasonic amplitudes and duration time on ASC extracted from sea bass (Lateolabrax japonicus) skin in 
control of the same temperature and frequency $\left(4^{\circ} \mathrm{C}\right.$, $20 \mathrm{kHz}$ ) were investigated. The collagens treated below $60 \%$ amplitude for $6 \mathrm{~h}$ still exhibited a typical type I collagen structure, including $\alpha 1, \alpha 2$ and $\beta$ chains, which were observed in sodium dodecyl sulfate polyacrylamide gel electrophoresis (SDS-PAGE) patterns. Gradual degradation occurred as the ultrasonic time lengthened and the amplitude increased, which was observed as the rapid increase of the components and the wide distribution of molecular weight [58]. Excessive physical forces generated from cavitation might break the hydrogen bonds among collagen molecules and weaken van der Waals interaction among the polypeptide chains, leading to collagen denaturation [59].

Microwave irradiation as heating energy source or transmission medium is still a new technology to be applied to the extraction of native collagen [60]. Li et al. [61] isolated collagen with papain from pigskin by microwave pretreatment at $25^{\circ} \mathrm{C}$ for $2 \mathrm{~min}$. The yield of collagen observably increased from $51.24 \%$ to $76.72 \%$. The collagen with intact structure was extracted from cattle hide by Cheng et al. [62] using microwave irradiation at $37^{\circ} \mathrm{C}$ for $7 \mathrm{~h}$ as the ratio of material to liquid $(0.5 \mathrm{~mol} / \mathrm{ml}$ acetic acid) was $1: 45(\mathrm{w} / \mathrm{v})$. Td of the collagen treated with microwave irradiation was $38.8^{\circ} \mathrm{C}$, which was similar to that of the collagen extracted under water bath heating $\left(38.91^{\circ} \mathrm{C}\right)$. The yield of collagen extracted by microwave irradiation was 1.5 times higher than that of traditional water bath heating. The thermal denaturation behavior of the bovine tendon collagen in acetic acid solution $(5.0 \mathrm{mg} / \mathrm{ml})$ during microwave irradiation and oil-bath heating was examined by combination of $C D$ and polarimetry [63]. The feature of native collagen is revealed in CD spectra at positive peak around $210-230 \mathrm{~nm}$ and at negative peak around 190$200 \mathrm{~nm}$ [64]. The positive peak $(223 \mathrm{~nm})$ of collagen treated microwave irradiation disappeared at $40^{\circ} \mathrm{C}$ and that of oil-bath heating disappeared at $50^{\circ} \mathrm{C}$. The significant change of relative optical rotation variable of collagen under microwave irradiation started at $25^{\circ} \mathrm{C}$, which was $9^{\circ} \mathrm{C}$ lower than that of oil-bath heating $\left(34^{\circ} \mathrm{C}\right)$. The thermal denaturation of collagen in acetic acid solution was more easily accelerated under microwave irradiation than under conventional heating. When being applied to extraction of collagen with a lower denaturation temperature, the microwave irradiation should be used with caution.

\section{4 lonic liquids pretreatment extraction}

Owing to the tight weave of collagen in tissues, some chemical reagents have been used to remove noncollagenous constituents and to loosen fiber contexture for extracting collagen easily $[65,66]$. Instead of traditional reagents, Ionic liquids (ILs) composed of bulky organic cations and small inorganic anions have been applied to the pretreatment of skin [67]. Choline thioglycolate (LD50-Oral-rat: $3400 \mathrm{mg} / \mathrm{kg}$ ) rather than sodium sulphide (LD50-Oral-rat: $246 \mathrm{mg} / \mathrm{kg}$ ) was used to remove hair from goat skin. The tensile strength and tear strength of the skin treated with choline thioglycolate were better than that of sodium sulphide, which were $22.7 \mathrm{MPa}, 56.4$ $\mathrm{N} / \mathrm{mm}$ and $15.8 \mathrm{MPa}, 40.1 \mathrm{~N} / \mathrm{mm}$ respectively [68]. 1butyl-3-methylimidazolium chloride ([BMIM] $[\mathrm{Cl}]$ ) as a fiber opening reagent was used to treat wet salted goat skin. The Ts values of the pelts treated with $0.25-1.0 \%$ [BMIM][Cl] $\left(108-116^{\circ} \mathrm{C}\right)$ were similar to that of conventional process $\left(112^{\circ} \mathrm{C}\right)$ [69]. 1-butyl-3-methylimidazolium tetrafluoroborate ([BMIM][BF4]) was employed in both the unhairing and fiber-opening processes of wet salted goat skin. The Ts values of the leather treated with [BMIM] [BF4] and that treated with calcium hydroxide and sodium sulfide were 111 and $116{ }^{\circ} \mathrm{C}$ respectively [70]. ILs could help to open collagen fibers and take little damage to the structure of collagen, which make ILs feasible to assist in extracting native collagen. Liu et al. [71] firstly used two ILs, namely 1-ethyl-methylimidazolium dicyanamide ([EMIM] $\left.\left[\mathrm{N}(\mathrm{CN})_{2}\right]\right)$ and 1-ethylmethylimidazolium tetrafluoroborate ([EMIM] $\left.\left[\mathrm{BF}_{4}\right]\right)$, of different concentrations (30, 50 and $70 \%)$ to pretreat calfskin at $4{ }^{\circ} \mathrm{C}$ for $24 \mathrm{~h}$ as the ILs/skin ratio was 10:1(w/w). Then PSC-s were extracted from the skins pretreated with the ILs, which were observed to always consist of $\alpha 1, \alpha 2$ and $\beta$ chains in SDSPAGE patterns. The extraction yield of collagen increased by about $9 \%$ after pretreating skins with the $70 \%$ ILs. The $\mathrm{Td}$ values of collagen decreased less than $1^{\circ} \mathrm{C}$ as the concentration of the ILs increased from 0 to $70 \%$. ILs might not destroy the triple helix but affect interaction among collagen molecules at low temperature.

The native collagen with distinct properties would be obtained by different extraction methods. Assistant means could help to raise the extraction yield but would destroy the triple helical structure of collagen under an inappropriate condition. The extraction methods and assistant means could be adjusted according to practical conditions and applications.

\section{The effect of collagen extracted from different sources on thermal stability}

In the collagen family, the fibril-forming collagens, especially type I-III collagens, have been the most wildly used because of the relatively abundant sources. Type I collagen is the major component in skin, bone, tendon, ligament and cornea. Type II collagen mainly exists in cartilage, vitreous body and nucleus pulposus. Type III collagen which often co-distributes with type I collagen resides in the skin, blood vessels and intestines [72]. The distribution of collagen members in organisms is quite different. The choice of source rich in desired collagen is of importance. Skin of porcine, bovine and sheep with 
low cost, alternatives such as deer, rabbit, chick, makes up the majority of collagen sources. Tendon of the rat-tail and bovine is the most commonly sources of type I collagen used by researchers. Cartilage is mainly used for isolating type II collagen [73]. Land mammals are always the major sources of collagen owing to the high abundance sources and low cost. Recently, collagen derived from marine sources has caused more investigator concern. Collagens of marine vertebrates and invertebrates such as fish (skin, scales and frame), jellyfish, sea cucumber, starfish and sponges have been exploited. Frog skin as amphibians source is also alternative [74, 75]. Physicochemical properties of collagen would be affected by varying amino acid compositions of different collagen types and sources. Herein, hydroxyproline (Hyp) content and denaturation temperature (Td) of collagen extracted from different species are listed in Table 2 and those of different tissues from the same sources are shown in Fig. 3.

Thermal stability of collagen significantly varies with different sources. A slight difference in thermal stability is presented in different tissues from the same sources. According to previous studies, the thermal stability of collagen from different living environments might be distinct. Gaill et al. [98] compared Td of the collagens extracted from annelids living in distinct habitats. Alvinella species were living directly at the vent walls with a fluctuating habitat temperature of 20 to $60^{\circ} \mathrm{C}$. Paralvinella was living in the lower temperatures of 15 to $20^{\circ} \mathrm{C}$. Shallow sea-water annelids inhabited constantly a cold environment $\left(10\right.$ to $\left.20^{\circ} \mathrm{C}\right)$. The $\mathrm{Td}$ values of collagens extracted from those three annelids were $45^{\circ} \mathrm{C}, 35$ and $28^{\circ} \mathrm{C}$ respectively. The thermal stability of carp scales collagen caught in summer was $1.8^{\circ} \mathrm{C}$ higher than that caught in winter [99]. Td of collagen extracted from orbicular batfish in the deep-see water was $1.7^{\circ} \mathrm{C}$ lower than that extracted from shallow-sea water [100].

Generally, the thermal stability of collagen extracted from terrestrial animals is higher than that of aquatic animals. Imino acids, especially Hyp, were speculated to improve the thermal stability of collagen because of their high content in the collagen of terrestrial animals. The $\mathrm{Td}$ values of native collagens isolated from chicken tendon and embryos were demonstrated to be $15^{\circ} \mathrm{C}$ higher comparing with that of the procollagens isolated without hydroxyproline [101, 102]. Hyp which benefited from the ability of making hydrogen bonds was proposed to have an important and unique role in the maintenance of the native structure of collagen [103]. Miles et al. $[104,105]$ further stressed the importance of hydroxyproline in stabilizing the triple helix. The major thermally labile domains were identified through the analysis of the triple helix fragments in collagen. The denaturation process initiated from the hydroxyproline deficient sequences in fibril-forming type I-III collagens as well as in non-fibril-forming type IV and IX collagens. Burjanadze and his colleagues [76] analyzed the relationship between 4-Hyp content $\left(N_{\mathrm{Hyp}}\right)$ and $\mathrm{Td}$ of the collagens extracted from various species such as tissues from fish, land animals and invertebrate by using curve-fitting analytical program (Table-Curve-Jandel). The simple Eq.

Table 2 Hydroxyproline content (residues/1000 total residues) and denaturation temperature (Td) of collagen from various species

\begin{tabular}{|c|c|c|c|c|c|c|c|c|c|c|c|}
\hline Tissues & Species & Hyp & Pro+Hyp & $\mathrm{Td} /{ }^{\circ} \mathrm{C}$ & Reference & Tissues & Species & Hyp & Pro+Hyp & $\mathrm{Td} /{ }^{\circ} \mathrm{C}$ & Reference \\
\hline \multirow[t]{18}{*}{ Skin } & Calf & 94 & 215 & 39.7 & {$[66]$} & Tendon & Rat tail & 94 & - & 36 & [76] \\
\hline & Procine & 97 & 220 & 40.8 & {$[77]$} & Cartilage & Calf & 95 & - & 39 & [76] \\
\hline & Sheep & 93 & 221 & 40 & {$[78]$} & & Sturgeon & 88 & - & 33 & [76] \\
\hline & Deer & 108.3 & 229.54 & 36.4 & {$[79]$} & Fish scale & Carpfish & 109 & 231 & 29 & {$[80]$} \\
\hline & Rabbit & 102 & 229 & 39 & {$[78]$} & Oreochromis niloticas & & 83 & 193 & 35.7 & [77] \\
\hline & Rat & 93 & 223 & 37 & {$[78]$} & & Pagrus major & 73 & 180 & 29.9 & [77] \\
\hline & Chick & 99 & 212 & 41 & {$[78]$} & & Snakehead & 75.6 & 192.7 & 30.3 & [81] \\
\hline & Bullforg & 54 & 167 & 30.3 & {$[82]$} & Bone & Sheep & 94.8 & 209.46 & 42.3 & [28] \\
\hline & Leather jacket fish & 83 & 192 & 29.3 & {$[83]$} & & Caltic cod & 15.7 & - & 14.4 & [84] \\
\hline & South catfish & 77 & 197 & 34.1 & {$[66]$} & Marine invertebrates & & & & & \\
\hline & Paddlefish & 85.5 & 197.9 & 28.2 & {$[85]$} & & Jellyfish (II) & 70 & - & 37.3 & [86] \\
\hline & Globefish & 82.1 & 189.7 & 26.9 & {$[85]$} & & Surf clam shell & 69 & 155 & 31.3 & [87] \\
\hline & Nile tilapia & 70 & 185 & 34.4 & {$[88]$} & & Sea cucumber & 67 & 151 & 30.2 & [89] \\
\hline & Pufferfish & 67 & 170 & 28 & {$[90]$} & & Suberites carnosus & 47 & 103 & 32.9 & [91] \\
\hline & Grass carp & 65 & 186 & 28.4 & {$[92]$} & & Axinella cannabina & 38 & 96 & 25.4 & [91] \\
\hline & Deep-sea fish & 61 & 160 & 15.7 & [33] & & Starfish & 111 & 219 & 33 & [93] \\
\hline & Antarctic ice fish & 47 & 147 & 6 & [94] & & D.singhalensis & 99 & 225 & 34.8 & [95] \\
\hline & Total & 1000 & 1000 & & & & Total & 1000 & 1000 & & \\
\hline
\end{tabular}




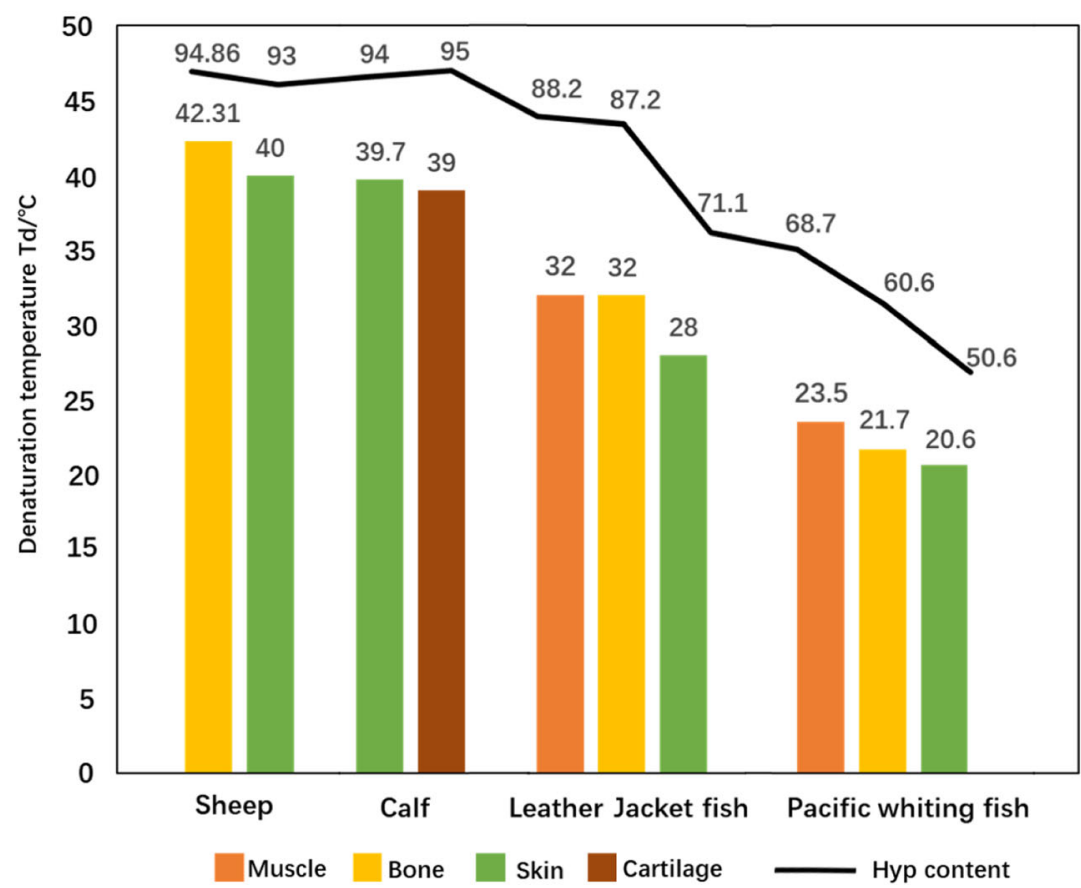

Fig. 3 Denaturation Temperature $\left(\mathrm{Td} /{ }^{\circ} \mathrm{C}\right)$ and Hydroxyproline Content (residues/1000 total residues) of collagen from varying tissues. Sheep [28, 78], Calf [66, 76], Leather Jacket fish [96] and Pacific whiting fish [97]

$\left(T d=69.9-3105 / N_{\text {Hyp }}\right)$ was linearized from all the data except for that of the ice fish collagens. For most collagens, the thermal stability is in the positive correlation with the content of Hyp. A few collagens of invertebrate deviate considerably from the trend. The collagen of Lumbricus terrestris (earthworm) had lower $\mathrm{Td}\left(22^{\circ} \mathrm{C}\right)$ but higher amount of Hyp ( 17\%) [106]. The collagen of Riftia pachyptila cuticle exhibited higher $\mathrm{Td}\left(37^{\circ} \mathrm{C}\right)$ but contained lower levels of imimo acids ( $5 \%) .18 \% \mathrm{Thr}$ rather than Hyp was fond in the Y position by analyzing the amino acid sequences of the collagen isolated from Riftia pachyptila cuticle. Thr was proposed to replace Hyp in the triple helix for stabilizing function [107]. The effect of the individual amino acid and various amino acid sequences on stability of collagen is difficult to achieved by direct determination of native collagen with complex structure. Crystallization of native collagen and collagen-like domains is necessary. Collagen-like peptides have been crystalized to further confirm the basic triple helix model and elucidate the hydrogen-bonding patterns in detail [108-111].

The relationship between amino acids and the thermal stability of collagen was evaluated via a "host-guest" peptide which had the following sequence -(Gly-Pro-Hyp) ${ }_{3}$ Gly-X-Y-(Gly-Pro-Hyp) $4^{-}$. The Gly-Pro-Hyp repeating sequence in both ends provided a stability triple-helical environment for the guest Gly-X-Y (GXY) triplet. All of the host-guest peptides had characteristic of the collagen triple helix in $C D$ spectrum. The melting temperature
(Tm) of all different GXY was determined by CD $[112,113]$. Initially, the most frequent 5 non-polar residues in collagens were evaluated by host-guest studies. The peptide where $\mathrm{GXY}=$ Gly-Pro-Hyp was the most stable $\left(\mathrm{Td}=44.5^{\circ} \mathrm{C}\right)$. The replacement of a single Pro or Hyp dropped the thermal stability $\left(20.7^{\circ} \mathrm{C}-39.9^{\circ} \mathrm{C}\right)[112]$. All 20 possible amino acids in the $\mathrm{X}$ and $\mathrm{Y}$ positions were further studied. (Gly-Pro-Hyp) ${ }_{8}$ had the highest $\mathrm{Tm}$ value of $47.3^{\circ} \mathrm{C}$. The change of identity in the $\mathrm{X}$ position showed a small effect on thermal stability $\left(31.9^{\circ} \mathrm{C}-47.3^{\circ} \mathrm{C}\right)$. The replacing of Hyp in the $\mathrm{Y}$ position leaded to large spread of thermal stability $\left(26.0^{\circ} \mathrm{C}-47.3^{\circ} \mathrm{C}\right)$. Arg in the Y position like Hyp is also one of the most stable residues, because Arg is involved in hydrogen bonds and hydrophobic interactions [113]. The importance of imino acids was confirmed. The effect of Hyp in the Y position on stabilization was greater than that of Pro in the $\mathrm{X}$ position.

For vertebrate collagen, Hyp as the form of $4 \mathrm{R}$ hydroxy-L-proline (4R-Hyp) is found exclusively in the Y position to confer extra stability $[114,115]$. Two controversial mechanisms of Hyp stabilizing the triple helix were explained by crystallographic evidences. One mechanism was pointed out by Brodsky and her colleagues [116, 117], that was Hyp stabilized triple helical structure by water mediated hydrogen bonds. Water bridge molecules linked the hydroxyl group of Hyp residues to a carbonyl group on the backbone of an adjacent chain via hydrogen bonds. The triple helical structure of $\mathrm{NH}_{2}$ Gly-(Gly-Pro-Hyp) ${ }_{4}$-Gly-Pro-Flp-(Gly-Pro-Hyp) ${ }_{3}$-GlyAc was less stable than that of $\mathrm{NH}_{2} \mathrm{Gly}-(\mathrm{Gly}-\mathrm{Pro}-\mathrm{Hyp})_{8}-$ 
GlyAc. The replacement of Hyp with Flp was suggested to disrupt the hydration induced by Hyp, because Flp could not form strong hydrogen bonds [118]. The other mechanism was proposed by Raines et al. $[119,120]$. Td of (Gly-Pro-Flp) 10 was much higher than that of (GlyPro-Hyp) ${ }_{10}$, which were 91 and $69^{\circ} \mathrm{C}$ respectively. Because Flp is more electronegative comparing with Hyp, the stereo electronic inductive effect rather than water bridges was suggested to play a major role in triple helix. Hyp was proposed to stabilize the trans conformation of the imide peptide bond through stereoelectronic inductive effect, because all peptide bonds are trans. In some invertebrate and basement membranes collagens, Hyp occurred in both $\mathrm{X}$ and $\mathrm{Y}$ positions [121, 122]. Hyp in the $\mathrm{X}$ position was demonstrated to exhibit effects of stabilizing or destabilizing on triple helix. Td of (GlyHyp-Hyp) ${ }_{10}$ was $4^{\circ} \mathrm{C}$ higher than that of (Gly-ProHyp) ${ }_{10}$. Hyp-induced stabilization in the $\mathrm{X}$ position attributed to the interchain dipole-dipole interactions between proximal hydroxy bonds of adjacent Hyp residues [123, 124]. Comparing with (Gly-Pro-Pro) ${ }_{10}$, the failure of (Gly-Hyp-Pro $)_{10}$ to form a triple helical structure demonstrated Hyp in the $\mathrm{X}$ position could destabilize the triple helix [120, 125]. Since Hyp preferred the exo ring pucker, Hyp was proposed to be improper for the $\mathrm{X}$ position where a Pro residue adopted the endo ring pucker to stabilize a triple helix [125, 126]. Hyp-induced stabilization in the $\mathrm{X}$ position is supposed to occur only when the residue in the $\mathrm{Y}$ position is able to provide extra-stabilizing interactions. Hyp-induced stabilization in the $\mathrm{Y}$ position is independent of the residue type in the $\mathrm{X}$ position [127].

Thr replaced Hyp in the Y position to stabilize the triple helix in the cuticle collagen of vestimentiferan Riftia pachyptila. The triple-helix structure was demonstrated to achieve only after glycosylation by analyzing a scale of synthetic Gly-Pro-Thr peptides [128, 129]. Glycosylated threonine was speculated to stabilize the triple helix in a way similar to proline ring pucker, inductive effects or hydrogen bonding [130].

Imino acids as a major role in most collagens make a contribution to thermal stability. Other mechanisms of stabilization, such as Arg in the Y position and glycosylation of Thr, might work in a collagen of lacking imino acids. The effects of amino acid compositions on the thermal stability of collagen mainly came from the studies of idealized sequences. Whereas, amino acid sequences are much more complex in native collagens than that in ideal model peptides. Collagen of various sources shows a different expression of molecules to satisfy the biological function.

For the first time, collagen model fragments with natural amino acid sequences were constructed by $\mathrm{Li}$ and her group [131] using computer simulation. To further study the effect of Hyp content on thermal stability of collagen molecules, the fragments of grass carp collagen were selected according to the distribution of Hyp content in diverse regions of amino acid sequences. The model fragments were optimized to fit the typical triple helix. A mathematical model was carried out to estimate the hydrogen bond energy of intact collagen chains according to the model fragments. The hydrogen bond energy between the collagen chains $(17.74 \mathrm{~J} / \mathrm{g})$ calculated by the mathematical model was consistent with the DSC results $(17.98 \mathrm{~J} / \mathrm{g})$. The lowest energy reduction $(1.247$ $\mathrm{kcal} / \mathrm{mol}$ ) was shown in the simulated fragment of the highest Hyp content (15.6\%) after heating simulation at $35^{\circ} \mathrm{C}$. The collapse of the triple helix began in the regions of less Hyp content and then in the regions of high Hyp content, as shown in the simulation of structural change of model fragments during heating process (Fig. 4). The physical and chemical properties of native collagen could be further explored by constructing collagen model fragments with natural amino acid sequences.

\section{The effect of different solvent systems on thermal stability}

Collagen is always used in form of solution or is developed with aqueous preparations. The triple helix of collagen is maintained by several interactions such as hydrogen bonds, electrostatic attractions and hydrophobic interactions. These interactions might be disturbed by the change of solvent systems, thus affecting the thermal stability of collagen. This review mainly discusses the thermal stability of collagen in different solvent systems from four aspects.

\subsection{The concentration of collagen}

$\mathrm{Td}$ of the collagen extracted from bovine skin in acid solution was observed to decrease by about $0.8^{\circ} \mathrm{C}$ as the collagen concentration increased from 5 to $20 \mathrm{mg} / \mathrm{ml}$ in Liu's study, which indicated collagen molecular state might change in different collagen concentrations [132]. Three collagen concentrations were chosen according to the critical aggregation concentration (CAC) of collagen (bovine skin) in acid solution [133]. $0.25 \mathrm{mg} / \mathrm{ml}$ expressed non-aggregation state of collagen molecules. 0.5 and $1.0 \mathrm{mg} / \mathrm{ml}$ exhibited critical aggregation and complicated aggregation state respectively. Transition temperature of collagen slightly decreased by $0.3^{\circ} \mathrm{C}$ as collagen concentration increased from 0.25 to $1.0 \mathrm{mg} /$ $\mathrm{ml}$. The morphology of collagen solution changed from homogenous to inhomogeneous and the collagen fibers gradually became denser with the increase of collagen concentration. The aggregation behavior was induced by increasing collagen concentration in acid solution, which was proposed to be largely mediated through the interactions of aromatic residues. The interaction between 


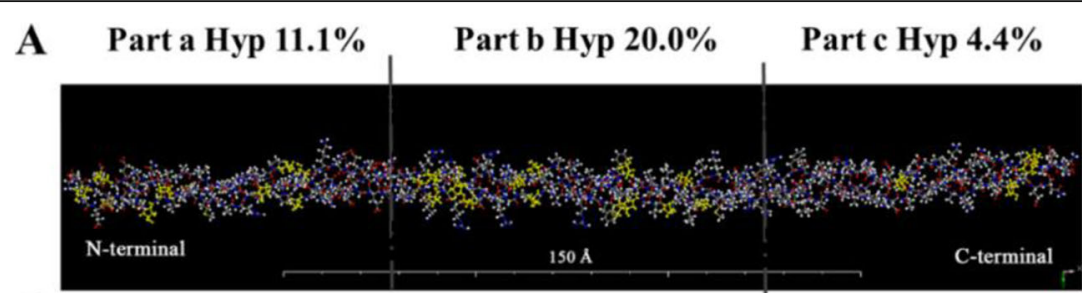

B

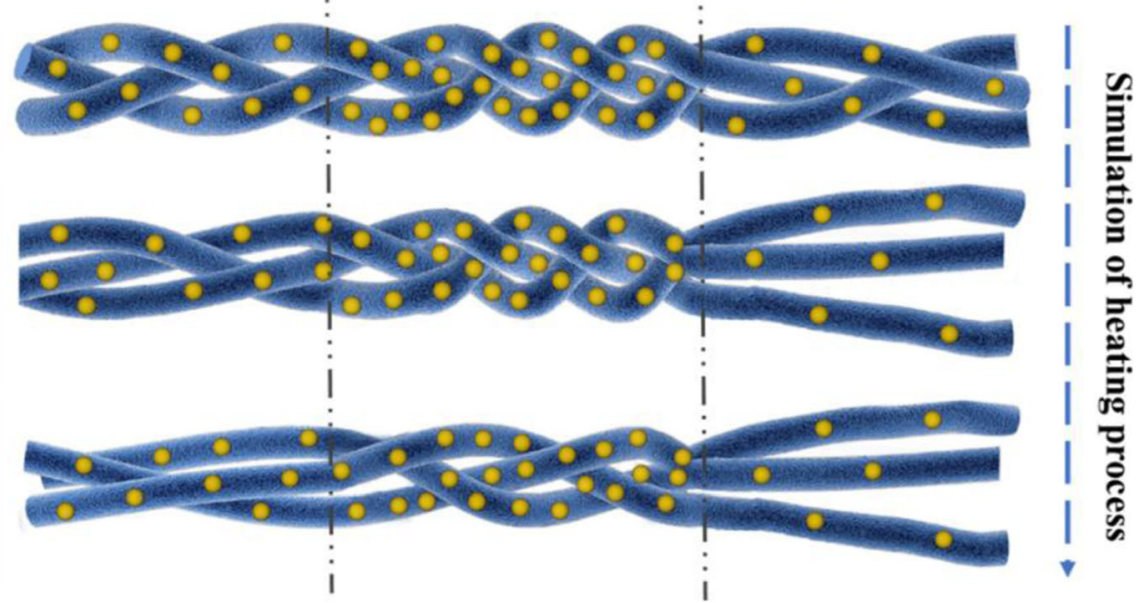

Fig. 4 (a) The optimal molecular model. The yellow-marked amino acid is Hyp. (b) The schematic diagram of structural changes of a collagen model during degeneration. The yellow dots represent the distribution of Hyp. Adapted with permission from [131]. Copyright @ 2019, American Chemical Society

the aromatic residues in one monomer and imino acids residues within another monomer caused the aggregation of collagen [134]. The triple-helical conformation was proposed to be buttress though ordered water networks between adjacent monomers [135]. In a higher collagen concentration, more hydrophobic microdomains were formed during the process of aggregation. Ordered water networks might be destroyed, which resulted in a slightly decrease of thermal stability. In the other hand, a higher rate of heat transfer occurred during heating process because of the shorter distance among collagen molecules in an aggregation state [133]. From a thermodynamic point of view, the aggregation is an entropy-driven process described as randomness reduction in the spatial arrangement of the collagen monomers in solution [136]. The thermal denaturation behavior of collagen could also be described as a thermodynamic process $[132,136]$. Lumry-Eyring model was the most probable mechanism for estimating the thermal denaturation of collagen and showed a process of gradual unfolding of triple-helical structure during heating. Collagen existed three states, namely native triple helix state, the partially unfolded state and the denatured state, during thermal denaturation. The quantity of those three states would be changed with the varying temperature and heating rates [137].

\subsection{The concentration of acetic acid}

Acetic acid (AA) is regarded as the most ideal solvent in extracting and dissolving collagen. Collagen could be efficiently extracted in and homogenously dispersed into AA solution due to the electrostatic interaction or lyotropic hydration of AA. Yang et al. [138] dissolved lyophilized collagen of calf skin into 0.1 2.0 M AA solution respectively and kept collagen concentration at $0.5 \mathrm{mg} / \mathrm{ml}$. The denaturation temperatures $\left(\mathrm{Tm}_{2}\right)$ of the collagen soluble in $0.1 \mathrm{M}$ AA solution and in $2.0 \mathrm{M}$ AA solution were 42.56 and $34.76^{\circ} \mathrm{C}$ respectively. $\mathrm{Tm}_{2}$ was a clear negative liner correlation with the AA concentration $\left(\mathrm{C}_{\mathrm{AA}}\right)$, as described in the formula $\mathrm{Tm}_{2}=44.30$ $1.93 \times C_{A A}$. The characteristic CD spectra of native collagen exhibits a positive peak around $210-230 \mathrm{~nm}$ and a negative peak around 190-200nm [64]. All samples exhibited the typical CD spectra of native collagen conformation. The ratio of positive to negative peaks (Rpn) could be used to indicate the integrity of triple helical structure. The Rpn values of collagen in $0.1 \mathrm{M}$ and 0.5 M AA solution almost the same, which were 0.132 and 0.133 respectively. Further increasing AA concentration, Rpn first increased to 0.145 and then decreased to 0.129 . Native collagen structure remained in the AA solution of different concentrations but the conformation of collagen was affected. Additionally, the morphology of 
collagen in low AA concentrations (0.1-1.0 M) was observed as inhomogeneous aggregation state. Collagen morphology gradually became homogenous and the fibers get thinner as the AA concentration was above 1.0 M. Disaggregation would take place in a higher AA concentration. The repulsion of $\mathrm{NH}_{2}{ }^{+}$groups would be enhanced with the increase of free $\mathrm{H}^{+}$concentration released by increasing AA concentration. The water mediated hydrogen bonds among collagen molecules would be gradually disrupted as AA concentration increased. Intra-and inter-molecular hydrogen bonds were weakened with the increase in AA concentration, thus leading to the decrease of collagen thermal stability.

\subsection{Different inorganic ion concentrations and species}

In aqueous solution, ions might interact with collagen and/or water molecules to control the state of collagen. The effect of inorganic salt on protein as "salting-in" and "salting-out" have been well known. Specific ion effects were first be proposed by Hofmeister [139], which was now known as the Hofmeister series. The Hofmeister series is the ordering of ions in terms of their ability to salt out or salt in proteins as follows: $\mathrm{SO}_{4}{ }^{2-}>\mathrm{HPO}_{4}{ }^{2-}>$ $\mathrm{CH}_{3} \mathrm{COO}^{-}>\mathrm{F}^{-}>\mathrm{Cl}^{-}>\mathrm{Br}^{-}>\mathrm{NO}_{3}^{-}>\mathrm{I}^{-}>\mathrm{ClO}_{4}^{-}>\mathrm{SCN}^{-}$and $\mathrm{Mg}^{2+}>\mathrm{Li}^{+}>\mathrm{Na}^{+}>\mathrm{K}^{+}>\mathrm{NH}_{4}{ }^{+}>\left(\mathrm{CH}_{3}\right)_{4} \mathrm{~N}^{+}$. Generally, kosmotropes on the left of $\mathrm{Cl}^{-}$and $\mathrm{K}^{+}$were called "water structure makers" which make the bulk water more ordered and collagen preferentially hydrated to keep the original state of collagen. Chaotropes on the right were called "water structure breakers" which reduce the strength of intrahelical hydration and promote the denaturation of collagen via increasing the translational and vibrational frequencies of the water molecules [140]. The effect is dominated by anions which are more polarizable and strongly hydratable [141, 142]. KomsaPenkova et al. [143] chose 12 inorganic salts to study the effect of different ion concentrations and species on thermal stability of collagen. The salts included sodium salts with $\mathrm{Cl}^{-}, \mathrm{SCN}^{-}, \mathrm{H}_{2} \mathrm{PO}_{4}{ }^{-}, \mathrm{HPO}_{4}{ }^{2-}, \mathrm{SO}_{4}{ }^{2-}$ anions and chloride salts with $\mathrm{Li}^{+}, \mathrm{K}^{+}, \mathrm{Na}^{+}, \mathrm{NH}_{4}^{+}, \mathrm{Ca}^{2+}$ cations. $\mathrm{Li}_{2} \mathrm{SO}_{4}$ and $\mathrm{NaN}_{3}$ were also measured. The salts were dissolved in $50 \mathrm{mM}$ acetic acid to get different concentrations. Then the salt solutions and collagen solutions (in $50 \mathrm{mM}$ acetic acid) were mixed at the ratio of 1:1 (v/ v) and the final collagen concentration was kept at 0.5 $\mathrm{mg} / \mathrm{ml}$. The change of the $\mathrm{pH}$ values of the samples, except $\mathrm{Na}_{2} \mathrm{HPO}_{4}$, between 3 and 4.5 was proposed not to affect Td. At low salt concentrations of below $20 \mathrm{mM}$, $\mathrm{Td}$ of the all collagen solutions decreased by about $0.2^{\circ} \mathrm{C}$ for every $1 \mathrm{mM}$ increase in concentration. At intermediate salt concentrations of roughly $20-500 \mathrm{mM}$, the anions dominated the change of thermal stability of collagen and followed the order $\mathrm{H}_{2} \mathrm{PO}_{4}{ }^{-} \geq \mathrm{SO}_{4}{ }^{2-}>\mathrm{Cl}^{-}>$ $\mathrm{SCN}^{-}$. The Td values of collagen in $\mathrm{NaH}_{2} \mathrm{PO}_{4}(20-500$
$\mathrm{mM})$ and in $\mathrm{Na}_{2} \mathrm{SO}_{4}(50-100 \mathrm{mM})$ slightly fluctuated as concentration increased, which were $37.6 \pm 0.3$ and 35.5 $\pm 0.1^{\circ} \mathrm{C}$ respectively. $\mathrm{NaSCN}$ and all the chloride salts decreased the thermal stability of collagen and the tendency induced by the former was more obvious. Td of collagen decreased by about $6^{\circ} \mathrm{C}$ as the concentration of $\mathrm{NaSCN}$ increased to150 $\mathrm{mM}$ and the same effect could be obtained in $450 \mathrm{mM} \mathrm{NaCl}$. The increase of the $\mathrm{Td}$ values in $\mathrm{Na}_{2} \mathrm{HPO}_{4}$ might be affected by the $\mathrm{pH}$ value because of the significant increase of $\mathrm{pH}$ from 6.0 at 10 $\mathrm{mM}$ up to 9.6 at $500 \mathrm{mM} \mathrm{Na}_{2} \mathrm{HPO}_{4} . \mathrm{SO}_{4}{ }^{2-}$ anions interacted specifically with collagen. $\mathrm{Td}$ of collagen existed both a lower value and a higher value in $\mathrm{Na}_{2} \mathrm{SO}_{4}(100$ $150 \mathrm{mM})$ and $\mathrm{Li}_{2} \mathrm{SO}_{4}(300-750 \mathrm{mM})$ solutions, for example, the $\mathrm{Td}$ values were $32.2^{\circ} \mathrm{C}$ and $45.4^{\circ} \mathrm{C}$ in $150 \mathrm{mM}$ $\mathrm{Na}_{2} \mathrm{SO}_{4}$ and were $36.3^{\circ} \mathrm{C}$ and $43.7^{\circ} \mathrm{C}$ in $300 \mathrm{mM} \mathrm{Li}_{2} \mathrm{SO}_{4}$. The reason was inferred to be the presence of a complex two-step denaturation process or two fractions of dissolved and salted-out collagens. At higher concentrations (above $500 \mathrm{mM}$ ), a precipitous increase of thermal stability took place due to the observable decrease of free water in collagen induced by salting-out.

\section{4 lonic liquids (ILs)}

Ionic liquids (ILs) are commonly defined as consisting of asymmetrical bulky cation and symmetrical small anion. ILs generally display low melting points and some are liquid at room temperature due to a larger volume distribution of the charge of the cation and anion [144, 145]. Organic cations in ILs mainly include imidazolium, ammonium, phosphonium, cholinium and pyridinium and anions can be various organic or inorganic ions. ILs of different concentrations and types would show distinct effect on the thermal stability of collagen, as reported by Tarannum and her colleagues [146, 147]. Collagen of rat tail tendon (RTT) was treated with diethyl methyl ammonium methane sulfonate (AMS) of different concentrations. The concentration of collagen was kept at 2.7 $\mu \mathrm{M}$ ( $\mathrm{pH} 4.0$ ) after being mixed with AMS at collagen/ AMS ratios from $1: 0.05 \%$ to $1: 10 \%(\mathrm{v} / \mathrm{v})$. RTT fibers were treated by $0.05-10 \%$ AMS at $25^{\circ} \mathrm{C}$ for $24 \mathrm{~h}$. Td of the collagen solutions slightly decreased by $1^{\circ} \mathrm{C}$ with the increase of AMS. The Td values of collagen fibers gradually reduced from $63^{\circ} \mathrm{C}(0 \% \mathrm{AMS})$ to $55^{\circ} \mathrm{C}$ (5\% AMS) and then obviously decreased to $48^{\circ} \mathrm{C}$ as AMS was $10 \%$. AMS was shown not to affect the secondary structure of collagen and just to decrease thermal stability at interfibrillary level [146]. RTT collagen solution was added with the other two ILs, namely bis-choline sulphate (BCS) and 1-butyl-3-methyl imidazolium dimethyl phosphate (IDP), of same concentration (10\%) respectively to make final collagen concentration of $1.33 \mu \mathrm{M}$ (pH 4.0) at $4{ }^{\circ} \mathrm{C}$. The small pieces of collagen fiber were prepared after incubation at $25^{\circ} \mathrm{C}$ for $24 \mathrm{~h}$ to further be 
determined by DCS and CD. Td of the collagen treated with $\mathrm{BCS}$ was $5^{\circ} \mathrm{C}$ higher and that of the collagen treated with IDP was $17^{\circ} \mathrm{C}$ lower than that of the native collagen fibers. The collagen added with BCS showed the typical CD spectrum of native collagen. However, both positive peak $(222 \mathrm{~nm})$ and negative peak (197 nm) completely disappeared in the $\mathrm{CD}$ spectrum of the collagen added with IDP [147]. Mehta et al. [148] found collagen could be dramatically stabilized by choline dihydrogen (cDHP). Collagen of RTT was added with cDHP of different concentrations from 0.05 to $10 \%(\mathrm{w} / \mathrm{v})$ to keep the final collagen concentration at $0.15 \mathrm{mg} / \mathrm{ml}(\mathrm{pH}$ 4.0). The collagen added with $0.05 \%(\mathrm{w} / \mathrm{v})$ genipin was considered as positive control (CG). The solutions were incubated at $4^{\circ} \mathrm{C}$ overnight and then air dried on polyethylene plates to form membranes. $\mathrm{Td}$ of the membranes were measured by microshinkage tester. Meanwhile, the degree of crosslinking (crosslinking efficiency) of the solutions were determined using TNBS assay. The Td values of collagen treated with cDHP showed a linearly upward with the increase of cDHP concentration, which increased by $20^{\circ} \mathrm{C}$ as cDHP reached to $10 \%$. Crosslinking efficiency of collagen added with $0.05 \% \mathrm{cDHP}$ was similar to CG (about 30\%). The crosslinking efficiency of collagen was remarkably increased as the concentration of cDHP above $0.05 \%$, which reached to $89 \%$ for $10 \%$ cDHP. As a potential crosslinker, phosphate anion of cDHP was postulated to attached to cationic functional groups of collagen via electrostatic interaction to make collagen chains closer, resulting in the formation of crosslinking among collagen molecules. The aggregation behaviors of collagen molecules (calf skin) in a novel acetic acid/1-ethyl-3-methylimidazolium acetate (AA/ [EMIM][Ac]) biphasic solvent was studied by Yang et al. [149]. The blends of collagen and AA/[EMIM][Ac] were kept the collagen concentration constant using the varying $\mathrm{AA} /[\mathrm{EMIM}][\mathrm{Ac}]$ ratios of 10:0 to $5: 5(\mathrm{v} / \mathrm{v})$ where AA was $0.1 \mathrm{M}$. The denaturation temperature of collagen decreased from 42.523 to $38.138^{\circ} \mathrm{C}$ and the average size of collagen fibers gradually decreased from 1947.66 to $806.06 \mathrm{~nm}$ as AA/[EMIM][Ac] rations increased from 10:0 to 5:5. The samples exhibited the typical SDSPAGE patterns of native collagen, including $\alpha 1, \alpha 2$ and $\beta$ chains. The hydrogen bonds formed by the amino hydroxyl and ester oxygen groups among adjacent collagen monomers were broken in the AA/[EMIM][Ac] solutions, because two stronger hydrogen bonds were formed between $\mathrm{Ac}^{-}$and the amino hydroxyl groups and between $\mathrm{EMIM}^{+}$and the ester oxygen groups. The thermal stability of collagen solution was weakened as [EMI$\mathrm{M}][\mathrm{Ac}]$ increased.

The dissolution and thermal stability of collagen in ILs of different polarity and concentrations were investigated by Liu et al. [150]. Tow EMIM-based ILs with anions of tetrafluoroborate $\left(\mathrm{BF}_{4}\right)$ and acetate $(\mathrm{Ac})$ were chosen. [EMIM] $\left[\mathrm{BF}_{4}\right]$ had low polarity and [EMIM] $[\mathrm{Ac}]$ had high polarity. $150 \mathrm{mg}$ lyophilized collagen was added to $30 \mathrm{~g}$ those two ILs respectively. The concentration of soluble collagen in $70 \%$ [EMIM] $\left[\mathrm{BF}_{4}\right]$ was just $0.02 \mathrm{mg} / \mathrm{ml}$ and that of collagen in [EMIM][Ac] increased from 1.94 for $10 \%$ [EMIM][Ac] to $3.57 \mathrm{mg} / \mathrm{ml}$ for $70 \%$ [EMIM][Ac]. $\mathrm{Td}$ of the insoluble collagen fibers treated with $70 \%$ [EMIM] $\left[\mathrm{BF}_{4}\right]$ was $61.2^{\circ} \mathrm{C}$ similar to the native collagen fibers $\left(61.9^{\circ} \mathrm{C}\right)$ and that of fibers treated with $70 \%$ [EMI$\mathrm{M}][\mathrm{Ac}]$ decreased to $50.6^{\circ} \mathrm{C}$. The collagen fibers treated with $[\mathrm{EMIM}]\left[\mathrm{BF}_{4}\right]$ were looser than the native ones, while the fibers derived from [EMIM][Ac] were much more sparsely distribution, as shown in Fig. 5. In the high polarity IL, the collagen fibers would become looser and easier mobile, resulting in the reducing of thermal stability. The thermal stability and fibril-formation of collagen (grass carp skin) in three EMIM-based ILs with anions of bromide (Br), chloride $(\mathrm{Cl})$ and acetate (Ac) were reported by Zhai et al. [151]. The collagen solution was mixed with equal volume of phosphate buffer ( $\mathrm{pH}$ 7.4) containing one of the three ILs $(0.05 \mathrm{M})$ and was kept the final collagen concentration at 1 $\mathrm{mg} / \mathrm{ml}$. The native collagen solution and the solutions treated with the ILs were incubated at $30^{\circ} \mathrm{C}$ for $2 \mathrm{~h}$ to be further determined by DSC. The solutions showed a typical native collagen $\mathrm{CD}$ spectrum. The $\mathrm{Td}$ values of native collagen fibers and the fibers treated with [EMIM] [Br], [EMIM][Cl] and [EMIM] $[\mathrm{Ac}]$ were $38.86,39.47,40.38$ and $50.9^{\circ} \mathrm{C}$ respectively. The diameters of collagen fibers showed a gradually upward trend in the order of $\mathrm{CH}_{3} \mathrm{COO}^{-}>\mathrm{Cl}^{-}>\mathrm{Br}^{-}>$ native collagen, which were 109.4 $\pm 32.6,96.5 \pm 20.8,91.8 \pm$ 18.8 and $75.8 \pm 14.3 \mathrm{~nm}$ respectively. The three ILs could promote the fiber-formation and then increased the thermal stability of collagen fibers.

Collagen is an amphoteric charged protein. Meanwhile, various types of ILs would exhibit a number of distinct properties such as polarity, hydrophobicity and hydrogen-bonding capability. The interaction between ILs and collagen might be highly specific and quite complex in nature. The structure and thermal stability of collagen would be vast affected by the different combination of the cations and anions in ILs.

\subsection{Alcohols}

In aqueous environment, collagen could fold into the most stable conformation through hydrophobic interactions among nonpolar amino acid residues. Additionally, the repulsive forces between water and nonpolar side chains of collagen could favor the ordering of water structure to stabilize the collagen [152]. The thermal stability of collagen was greatly affected by adding alcohols which included glycerol, monohydric alcohols and dihydric alcohols. 


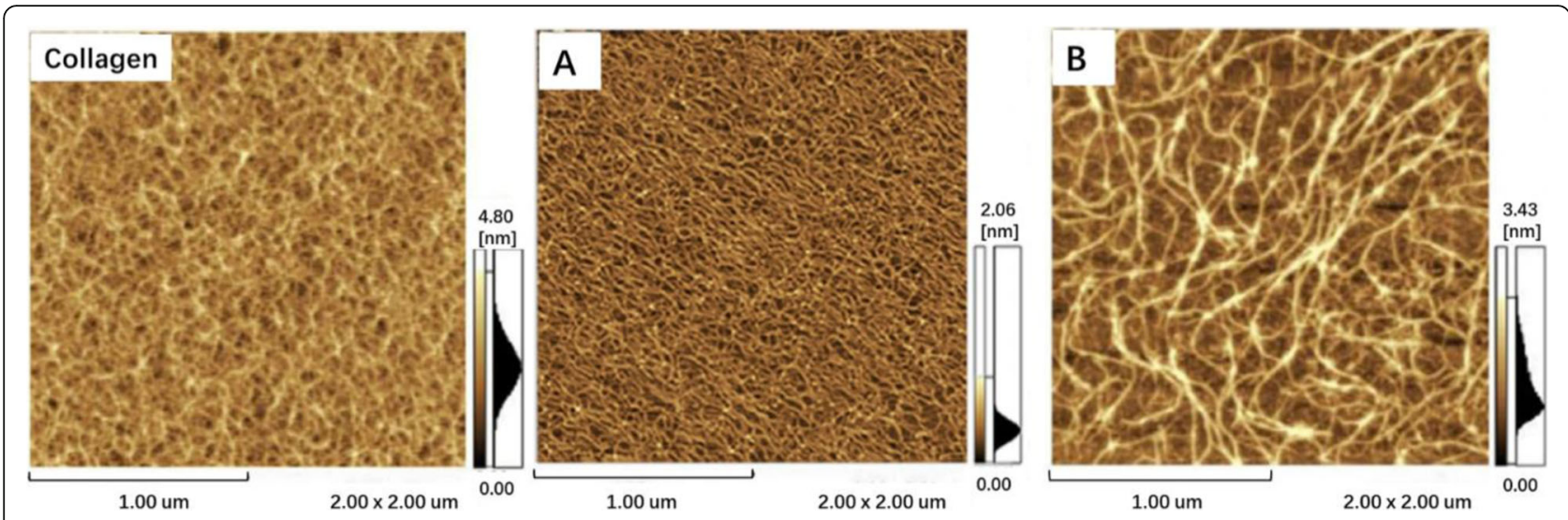

Fig. 5 AFM images of the native collagen and the insoluble collagen fibers derived from 70\% [EMIM][BF 4 (a) \& [EMIM][Ac] (b) respectively. Adapted with permission from [150]. Copyright @ 2019, Springer Nature

The effect of glycerol (Gly) on collagen was studied by Penkova et al. [153, 154]. $0.5 \mathrm{mg} / \mathrm{ml} \mathrm{PSC-s} \mathrm{of} \mathrm{calf} \mathrm{skin}$ (CSC), sheep skin (SSC), RTT (RTC) and human placenta (HPC) were chosen to be mixed with glycerol of different concentrations $(0-4 \mathrm{M})$. Td of the samples was positive linear dependent with the glycerol content. The equations were given as $T d=40.45+1.15 \times[$ Gly] (CSC), $T d=40.68+0.84 \times[G l y](\mathrm{SSC}), T d=40.46+0.71 \times[\mathrm{Gly}]$ (RTC), $T d=40.74+0.95 \times[G l y]$ (HPC). The collagen was proposed to preferred to interact with Gly rather than water. Every individual polypeptide $\alpha$-chain of collagen was stabilized through hydrogen bonding which was formed between the hydroxyl groups of Gly and Hyp residues within two neighboring triplets [153]. The effect of Gly on collagen during denaturation was further studied. $0-3 \mathrm{M}$ Urea and $0-0.15 \mathrm{M} \mathrm{NaCl}$ were chosen as the reagents of destabilizing collagen. The effect of those two reagents destabilizing collagen were reduced owing to the presence of the Gly. The dependence of $\mathrm{Td}$ on the urea and sodium chloride concentration in the presence of 0-3M Gly showed a set of parallel lines which were shifted upward by about $1^{\circ} \mathrm{C}$ per $1 \mathrm{M}$ glycerol [154]. The solvation shell surrounding collagen molecules were stabilized, because Gly with greater ability of forming hydrogen bonds was preferential binding with water [155]. The collagen was stabilized by Gly.

The thermal stability and aggregation behavior of collagen in Gly solution and 2-propanol solution were studied by Li et al. [156, 157]. Lyophilized collagen of calf skin was dissolved into $0.1 \mathrm{M}$ acetic acid containing 0.5 $-3 \mathrm{M}$ Gly or 2-proanol. The final collagen concentration was kept at $1 \mathrm{mg} / \mathrm{ml}$. The transition temperature $(\mathrm{Tm})$ of the collagen was positive linear dependent with the concentration of Gly but was negative linear dependent with the concentration of 2-proanol. The equations were given as $T m=41.45+0.929 \times[G l y], T m=41.44-1.638 \times[2-$ proanol]. Additionally, the mean diameter of collagen aggregates in 2-propanol showed higher and that of in Gly exhibited lower than that of the pure collagen aggregates, as shown in Fig. 6. The intermolecular aggregation was induced by the increase of hydrophobic residues in 2-propanol solution. The aggregation behavior of collagen was hampered in Gly due to the interaction between Gly and collagen. Aliphatic alcohols could promote the solubility of hydrophobic residues of collagen into the solvent medium to weaken hydrophobic bonds, thus destabilizing the triple helix $[158,159]$. The effect of monohydric alcohols with different specific dielectric constant $(\varepsilon r)$ on the collagen was reported by Nezu et al. [160]. Water has the $\varepsilon r$ value of above 80 and many organic compounds have smaller $\varepsilon r$ values. The lower $\varepsilon r$ value of alcohols, the lower affinity between water and alcohols. Methanol $\left(n-\mathrm{C}_{1} \mathrm{OH}\right)$, ethanol $\left(\mathrm{n}-\mathrm{C}_{2} \mathrm{OH}\right)$, 1propanol $\left(\mathrm{nC}_{3} \mathrm{OH}\right)$ and1-hexanol $\left(\mathrm{n}-\mathrm{C}_{6} \mathrm{OH}\right)$ were chosen, whose $\mathrm{Er}$ values were 33.0, 25.3, 20.8 and 13.0 respectively. Calfskin collagen was added with the alcohols of different concentrations (wt\%) to obtain a constant collagen concentration at $\mathrm{pH}$ 3.0. Precipitation of collagen from solution would occur in a higher concentration of solvents [161], thus the thermal behavior of collagen was observed mainly in low concentrations of monohydric alcohols $(<40 \%)$. The Td values of collagen solutions decreased with the increase of monohydric alcohols concentration. The tendency was more evident in the alcohols of a lower specific dielectric constant $(\varepsilon r)$. $\mathrm{Td}$ of the collagen in $20 \% \mathrm{n}-\mathrm{C}_{1} \mathrm{OH}, \mathrm{n}-\mathrm{C}_{2} \mathrm{OH}$ and $\mathrm{n}$ $\mathrm{C}_{3} \mathrm{OH}$ decreased by about 1,4 and $7{ }^{\circ} \mathrm{C}$ respectively. The hydrophobic interactions among collagen molecules were weakened as a more hydrophobic alcohol was added, which leaded to a lower Td. Gopinath et al. [162] investigated the effect of ethanol on the triple helix of collagen. $4 \mathrm{mg} / \mathrm{ml}$ collagen (RTT) stock solution was prepared by dissolving lyophilized collagen into $50 \mathrm{mM}$ acetic acid. The final collagen solution $(0.4 \mathrm{mg} / \mathrm{ml})$ was 


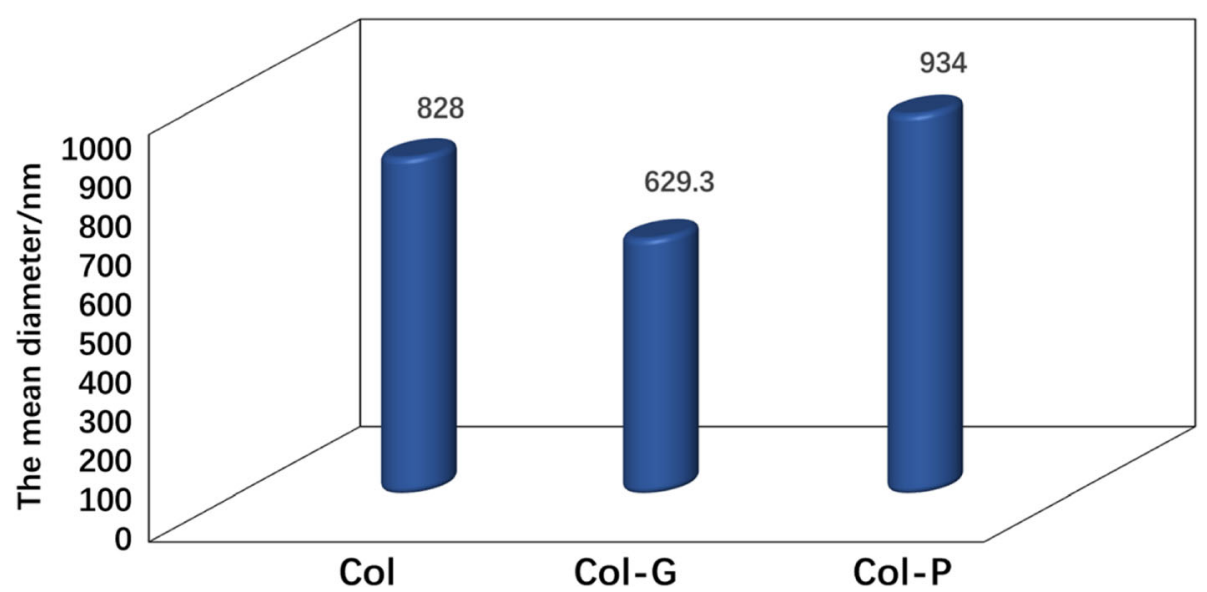

Fig. 6 The mean diameter of collagen aggregates in collagen (Col), collagen-glycerol (Col-G) and collagen-2-propanol (Col-P) [157]

prepared through adding appropriate volumes of ethanol of different concentrations and $50 \mathrm{mM}$ acetic acid into collagen stock solution $(4 \mathrm{mg} / \mathrm{ml})$. The collagen solution gradually turned into a gel in the ethanol with concentration above $50 \%$ due to the dehydration effect of ethanol. Therefore, collagen solutions in $0-40 \%$ ethanol were further studied. Melting temperature (Tm) of the solutions was determined by $\mathrm{CD}$. The Tm values of collagen gradually decreased from $40(0 \%$ ethanol $)$ to $34^{\circ} \mathrm{C}$ ( $40 \%$ ethanol). The characteristic CD spectrum of native collagen could be observed from the solutions. The molar ellipticity at $220 \mathrm{~nm}$ in the presence of ethanol $(10 \%-40 \%)$ was higher than that in the absence of ethanol. The collagen molecules became closer owing to the dehydration effect of ethanol, which could further disrupt the water network surrounding collagen monomers and water-mediated hydrogen bonds among collagen molecules. The change of molar ellipticity of collagen at $220 \mathrm{~nm}$ in various alcohols was studied by Usha et al. [163]. RTT collagen was mixed with $0.05-0.2 \mathrm{M}$ methanol and ethanol respectively. $0.2 \mathrm{M}$ Gly, n-propanol and propane 1,2-diol were added into collagen solution respectively as well. The collagen of constant concentration $\left(2 \times 10^{-6} \mathrm{M}\right)$ was measured by $\mathrm{CD}$. The molar ellipticity at $220 \mathrm{~nm}$ of collagen increased with the increase in concentration of methanol and ethanol and that of the collagen in 0.2M Gly, n-propanol and 1,2propanediol was lower than that of the pure collagen. The reason is still not clear. The collagen molecules would become closer and the water-mediated hydrogen bonds among collagen molecules might be destroyed in methanol and ethanol due to dehydrating effect. The hydrophobic residues of collagen would be more easily exposed in solvent after adding an alcohol of a lower polarity, which causes the secondary structure of collagen to become loose. Both mechanisms could make the triple helix require less energy to unfold during heating.
Collagen shows a lower thermal stability in monohydric alcohols.

The effect of a number of substituted diols on the thermal stability of collagen was investigated by Hart et al. [164]. A set of diols with different hydrocarbon chains and hydroxyl position included ethylene glycol, propan-1,3-diol, propan-1,2-diol, butane-1,4-diol, butane-1,3-diol, pentane-1,5-diol and hexane-1,6-diol. Calfskin collagen solution was added with these diols respectively and kept a constant collagen concentration for further determining melting temperature $(\mathrm{Tm})$ by optical rotation. Tm of the collagen in ethylene glycol and propan-1,3-diol increased and that of the collagen in the other diols decreased as the concentration of diols increased. The decreased tendency of Tm became more obviously as the hydrocarbon chains of diols lengthened. The collagen could be stabilized in the hydroxylterminated diols with short chain, probably because the diols similar to Gly have the ability of forming hydrogen bonds with Hyp residues of collagen. The stabilization of collagen could not be obtained in propan-1,2-diol, speculating the reason is that the two hydroxyls are too close to form "link" among collagen molecules. The thermal stability of collagen kept decreasing as the hydrocarbon chains lengthened, because the nonpolar groups which dominated in a longer chain diol promoted the exposure of hydrophobic residues within collagen chains into solvent.

\section{The effect of blending with polymers on thermal stability}

The disadvantages of collagen, such as low thermal stability, weak mechanical property and poor water \& enzymatic degradation resistance, would limit its applications. The blending of collagen and other polymers is the easiest way to obtain collagen-based biomaterials of improved properties. Natural polymers and 
biocompatible synthetic polymers with desirable biological features and mechanical properties are usually used to blend with collagen. The blends are usually prepared in solution and then manufactured into hydrogels, scaffolds, sponges, nanofibers or films. The thermal stability and miscibility of the blends in solution are important for further processing. The miscibility is judged by the comparation of the specific viscosity $([\eta] \exp m)$ and the ideal intrinsic viscosity $[\eta] i m$ of the blends. The blends are compatible as $[\eta] \exp m>[\eta] i m$ and are incompatible as $[\eta] \exp m<[\eta] i m$ [165].

\subsection{Natural polymers}

As natural polymers with excellent biocompatible and biodegradable properties, Chondroitin sulfate (CS), Hyaluronic acid (HA), Hydroxypropyl methylcellulose (HPMC), Carboxymethyl cellulose (CMC), Chitosan $(\mathrm{CH})$ and Alginic acid have been commonly used to blend with collagen. The chemical structure of those nature polymers is presented in Scheme 1. CS and HA as linear polyanions belong to the class of macromolecules known as glycosaminoglycans (GSG). Cellulose, $\mathrm{CH}$ and Alginic acid belong to polysaccharide with a highly ordered chemical structure. All those polymers contain abundant hydroxyl groups. Expect for HPMC and $\mathrm{CH}$, the others contain negatively charged group such as sulfo and/or carboxyl groups, which easily form precipitate with positively charged collagen in acid solution due to the strong electrostatic interaction. The charge shielding is necessary to obtain a miscible binary blend. The addition of $\mathrm{NaCl}$ is an effective approach.

The properties of the blends of collagen $(\mathrm{Col})$ with CS or HA and the interaction between collagen and CS or HA were studied by Li ang her groups [166-169]. Lyophilized collagen and chondroitin 4-sulfate (C4S) were dissolved in the phosphate buffered saline (PBS including $10 \mathrm{mmol} / \mathrm{L}$ phosphate and $100 \mathrm{mmol} / \mathrm{NaCl}$ ) at $\mathrm{pH} 7.4$ respectively to prepare the stock solutions. The $\mathrm{Col} / \mathrm{C} 4 \mathrm{~S}$ blends were obtained after mixing those two stock solutions at varying $\mathrm{Col} / \mathrm{C} 4 \mathrm{~S}$ weight ratios of 100/ $0-20 / 80$. The final collagen concentration was kept at 1 $\mathrm{mg} / \mathrm{ml}$ by adding suitable PBS. The solutions were incubated at $37^{\circ} \mathrm{C}$ for $60 \mathrm{~min}$ to form cofibrils. The thermal stability of cofibrils increased with the increase of the C4S content. The maximum transition temperature (Tm) of the cofibrils evidently increased from 42.7 to 53.9 at the $\mathrm{Col} / \mathrm{C} 4 \mathrm{~S}$ ratios of $100 / 0-91 / 9$ and then reached to $61.9^{\circ} \mathrm{C}$ at ratio of $70 / 30$. The increased tendency became slow at a ratio $>50 / 50$ and $\mathrm{Tm}$ was $65.8^{\circ} \mathrm{C}$ at ratio of $20 / 80$. The microfibrillar became large and order from small and disorder as C4S increased. Additionally, the D-periodicity of the cofibrils could be observed as ratios were $20 / 80$ and $80 / 20$. The selfassembly was carried out according to the original model and was accelerated after the addition of CS4, which promoted the thermal stability of cofibrils [166]. The properties of the blends of collagen and HA was also studied. Tris- $\mathrm{HCl}$ at $\mathrm{pH} 7.2$ was used as the solvent. The blends were prepared at various $\mathrm{Col} / \mathrm{HA}$ weight ratios of $8 / 2,5 / 5$ and $2 / 8$ and then lyophilized. Td of the sponges at ratios of $8 / 2,5 / 5$ and $2 / 8$ were $56,61.3$ and $69.5^{\circ} \mathrm{C}$ respectively. The morphology of the sponge at ratio of $5 / 5$ contained the least sheet structure and exhibited the most homogeneous comparing with that of the sponges as ratios were $8 / 2$ and $2 / 8$ [167]. The hydrogen bonds between collagen and CS or HA was observed in the further studies using FTIR (Fourier transform-infrared) and 2D correlation FTIR analysis. $0.25 \mathrm{~mol} / \mathrm{L} \mathrm{NaCl}$ at $\mathrm{pH} 7.4$ was used as solvent. The $\mathrm{Col} / \mathrm{CS}$ blends were prepared at $\mathrm{Col} / \mathrm{CS}$ weight ratios of 100/0-9/91. The blends were
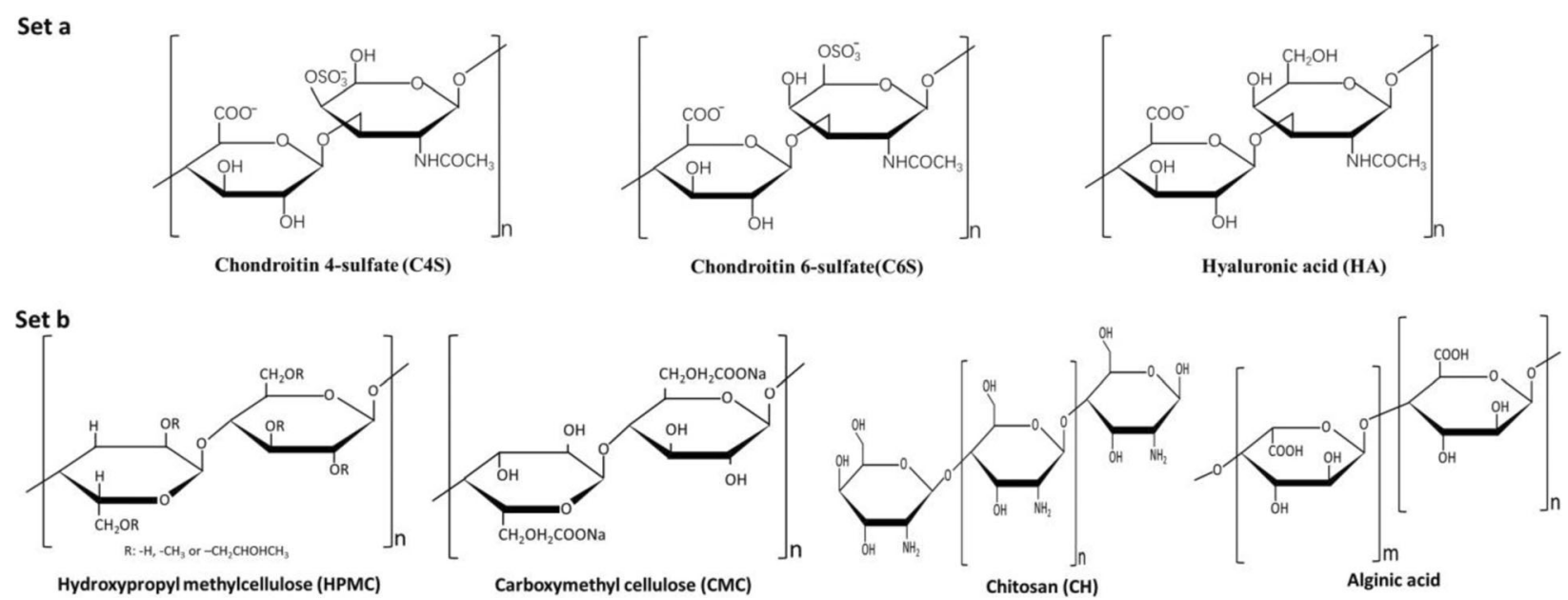

Scheme 1 Chemical structures of Chondroitin 4-sulfate, Chondroitin 6-sulfate, Hyaluronic acid, Heparin (set a) and Hydroxypropyl methylcellulose, Carboxymethyl cellulose, Chitosan, Alginic acid (set b) 
judged to be miscible, because $[\eta] \exp m$ was always higher than $[\eta] i m$. The evidence of interaction between collagen and CS came from the shift of the amide I band and the decrease of the intensity of amide II band of collagen as Col/CS ratios changed from 100/0 to 20/80. The hydrogen bond was formed between hydroxyl groups of $\mathrm{CS}$ and $\mathrm{C}=\mathrm{O}$ group of collagen as the CS content was below $50 \mathrm{wt} \%$ because of the charge shielding effect of $\mathrm{NaCl}$. When CS content was more than 50 $\mathrm{wt} \%$, the electrostatic interactions was formed between carboxyl or sulfate group of CS and amino group of lysine or guanidine group of arginine residues as well as hydrogen bonds between $\mathrm{C}=\mathrm{O}$ group of $\mathrm{CS}$ and amino groups of collagen [168]. The similar measurement was used to analyze the interaction between collagen and $\mathrm{HA}$. The blends of collagen and $\mathrm{HA}$ in $0.2 \mathrm{~mol} / \mathrm{L} \mathrm{NaCl}$ solution were prepared at the $\mathrm{Col} / \mathrm{HA}$ weight ratios of $100 / 0-0 / 100$ and then air-dried. The red-shift of amide I bond and blue-shift of amide II bond of collagen were observed from FTIR spectra, which demonstrated the existence of interaction between collagen and HA. The hydrogen bond between hydroxyl group of $\mathrm{HA}$ and $\mathrm{C}=\mathrm{O}$ group of collagen would be formed as HA content increased from 0 to $50 \%$ and that between $\mathrm{C}=\mathrm{O}$ group of $\mathrm{HA}$ and $\mathrm{N}-\mathrm{H}$ group of collagen was generated as HA content was 50\%-90\% [169]. The physicochemical and biological properties of the blends might be related to the different $\mathrm{Col} / \mathrm{CS}$ or $\mathrm{Col} / \mathrm{HA}$ ratios at which the interactions between collagen and those two polymers were different.

Cellulose with highly hydrophilic property cannot be soluble in a common solvent owing to strong inter- and intra-molecular hydrogen bonds. As cellulose derivatives, HPMC and CMC of highly water-solubility are usually used to blend with collagen. HPMC is a typical nonionic polysaccharide and CMC is anionic. The properties of the collagen/HPMC blends were investigated by $\mathrm{Li}$ and her group [170-172]. The blend solutions were prepared by mixing $15 \mathrm{mg} / \mathrm{L}$ collagen with $15 \mathrm{mg} / \mathrm{L}$ HPMC solution $(0.1 \mathrm{M}$ acetic acid as the solvent) at the Col/HPMC ration of $1 / 1(\mathrm{w} / \mathrm{w})$ and then air-dried at room temperature. The endothermic peak of the $\mathrm{Col} / \mathrm{HPMC}$ film was $6^{\circ} \mathrm{C}$ higher than that of the collagen film. The tensile strength of the film increased by $7.1 \mathrm{Mpa}$ comparing with the collagen film [170]. The thermal stability of $\mathrm{Col} / \mathrm{HPMC}$ gels at different $\mathrm{Col} / \mathrm{HPMC}$ weight ratios also be studied. PBS (pH 7.2) containing $100 \mathrm{mM} \mathrm{NaCl}$ was used as the solvent. The blends of collagen and HPMC were prepared at the ratios of $0 / 1-3 / 1$ and the collagen concentration was kept at $1 \mathrm{mg} / \mathrm{ml}$. The blend solutions were then incubated at $37^{\circ} \mathrm{C}$ for $60 \mathrm{~min}$. The thermal stability of hydrogels was determined by turbidity measurement at $46^{\circ} \mathrm{C}$. The lower reduction of turbidity, the higher thermal stability. The values of reduction in turbidity of the hydrogels mixed with HPMC were lower than that of the native collagen (49.8\%), which indicated the thermal stability of Col/HPMC was increased. The thermal stability of hydrogels exhibited the tendency of increase before decrease and reached to the highest at ratio of $0.25 / 1$ where the value of reduction in turbidity was $24.5 \%$ [171]. The interaction between collagen and HPMC varied with the different $\mathrm{Col} / \mathrm{HPMC}$ ratios. The Col/HPMC blends were prepared by mixing the two solutions (in $0.1 \mathrm{M}$ acetic acid solution) at the ratios of 10/0-0/10 and kept the collagen concentration at $5 \mathrm{mg} / \mathrm{ml}$. The blends showed incompatible as the HPMC content was above $50 \%$ under which $[\eta] \exp m$ was lower than $[\eta] i m$. The hydrogen bonds between HPMC and collagen were observed in 2D correlation FTIR spectrum and became weaker at a ratio above $7 / 3$. The hydrogen bonds tended to be formed among HPMC molecules, which resulted in weakening of interaction between collagen and HPMC [172]. Collagen whose isoelectric point is near physiological $\mathrm{pH}$ could not be dissolved in neutral solution. The acylation of collagen could solve the problem through converting the amino groups of lysine residues to carboxy groups [173]. Zhang et al. [174] used the deionized water as the solvent to blend succinylated collagen (SC) and CMC at different ratios of $10 / 0-0 / 10(\mathrm{v} / \mathrm{v})$. The blends were incompatible $([\eta] \exp m<[\eta] i m)$ as the ratios were $3 / 7$ and $1 / 9$. The denaturation temperature of blends increased by $0.9^{\circ} \mathrm{C}$ at ratio of $5 / 5$ and then decreased by $0.2^{\circ} \mathrm{C}$ and $0.5^{\circ} \mathrm{C}$ as ratios were $3 / 7$ and $1 / 9$ respectively comparing with $\mathrm{SC}$. The hydrogen bonds and electrostatic interactions between SC and CMC could improve the stability of the blends as the content of CMC was below $50 \%$. The interaction between SC and CMC would gradually be weakened with the increase of CMC content due to preferential formation of hydrogen bonds among CMC molecules, which decreased the thermal stability of the blends.

$\mathrm{CH}$ containing free amino groups is the only alkaline natural polysaccharide. Fu et al. [175] studied the properties of collagen $/ \mathrm{CH}$ membranes. The blends solution could be obtained by mixing $3 \mathrm{mg} / \mathrm{ml}$ collagen solution and $2 \% \mathrm{CH}$ at virous volume ratios of $4 / 1-1 / 4$ and then air-dried. $\mathrm{Td}$ of the membranes at $\mathrm{Col} / \mathrm{CH}$ ratio of $4 /$ 1 was $10^{\circ} \mathrm{C}$ higher and that of the membranes at other ratios was lower than that of the native collagen membrane. When $\mathrm{CH}$ content was above $40 \%$, the collagen fibers became remarkably loose and $\mathrm{CH}$ evenly distributed around collagen fibers observed in AFM images. Sionkowska et al. [176] using X-ray diffraction detected the helix structure in the collagen/ $\mathrm{CH}$ films gradually was lost as $\mathrm{CH}$ content increased. $0.5 \mathrm{M}$ acetic acid was used as the solvent in the study. The blends were prepared to contain different collagen contents of $0-100 \%$ and then dried in vacuum at room temperature. The 
solutions were miscibility, because $[\eta] \exp m$ were always higher than $[\eta] i m$. The characteristic peaks of native collagen in the solutions, which were observed by $\mathrm{X}$-ray diffraction, gradually disappeared as the $\mathrm{CH}$ content increased. The hydrogen bonding was formed between $-\mathrm{OH}$ groups of $\mathrm{CH}$ and $-\mathrm{NH}_{2}$ groups of collagen as well as between the end groups $\left(-\mathrm{COOH}\right.$ and $\left.-\mathrm{NH}_{2}\right)$ of collagen and $-\mathrm{OH}$ and $-\mathrm{NH}_{2}$ groups of $\mathrm{CH}$. The appearance of new hydrogen boning networks was speculated to alter the collagen helical character, thus affecting the thermal stability.

Alginic acid is a linear anionic copolymer arranged as homopolymeric or heteropolymeric block. In Mitra's study [177], alginic acid was regarded as a potential "cross-linker" for collagen. 0.5\% collagen of bovine skin was added with alginic acid solution of different concentrations (PBS, $\mathrm{pH}$ 6.5) at the $\mathrm{Col} /$ Alginic acid ratio of $3 /$ 1. The blend solutions were incubated for overnight at $4^{\circ} \mathrm{C}$ and then air-dried at $37^{\circ} \mathrm{C}$ for $12 \mathrm{~h}$. The solution of Glutaraldehyde (1.5\%) crosslinking collagen was carried out as a comparison. As alginic acid concentration was $1.5 \%$, the melting temperature of the films gradually increased to $150^{\circ} \mathrm{C}$, which was similar to the comparison $\left(151^{\circ} \mathrm{C}\right)$ and much higher than that of the native collagen film $\left(96.98^{\circ} \mathrm{C}\right)$. The crosslinking degree kept constant after adding alginic acid at a concentration above $1.5 \%$. The biologically active lactone ester was proposed to be formed in alginic acid due to loss of water during film formation and then reacted with free- $\mathrm{NH}_{2}$ groups of lysine residues in collagen chains, which formed chemical crosslinks among collagen molecules to improve the thermal stability. The thermal stability decreased as alginic acid concentration was further increased. Melting temperature shifted towards left might be caused by unreacted alginic acid whose melting temperature was about $90^{\circ} \mathrm{C}$.

\subsection{Biocompatible synthetic polymers}

Water soluble synthetic polymers with desirable biocompatibility, physiological inertia and plasticity, such as Poly-vinyl-alcohol (PVA), poly-vinyl-pyrrolidone (PVP), poly-ethylene-glycol (PEG) and poly-D, L-lactide-co-glycolide (PLGA), have broad range of applications. The thermal stability and properties of collagen blending with those polymers have been investigated. Collagen are commonly blended with PVA and PVP which have been wildly applied in various fields. The properties of Col/PVA blends were studied by Lai et al. [178]. 2.1wt\% blends were obtained after mixing the collagen and PVA solution at different Col/PVA weight ratios and then lyophilized. Dynamic denaturation temperature of the blends increased from $33.0^{\circ} \mathrm{C}$ for $100 / 0$ to $35.6^{\circ} \mathrm{C}$ for $20 /$ 80. The interaction between collagen and PVA showed the strongest as the contents of PVA were $20-30 \%$, which was demonstrated by analysis of FTIR. The formation of hydrogen bonds between collagen and PVA would be weakened at a higher content of collagen or PVA. The miscibility of collagen and PVA was reported by Sarti and Scandola [179]. The Col/PVA complexes with different PVA contents were air-dried at room temperature to obtained the films. $\mathrm{Td}$ of the native collagen film was $117^{\circ} \mathrm{C}$ and the glass transition temperature ( $\mathrm{Tg}$ ) of PVA was $50^{\circ} \mathrm{C}$. The $\mathrm{Td}$ values of the films showed an upward tendency with the increase of PVA content and increased by $14^{\circ} \mathrm{C}$ at PVA content of $70 \%$. Two distinct peaks of the Col/PVA films could be evidently observed in DSC curves, especially when the contents of PVA were $70 \%$ and $50 \%$, which accorded with $\mathrm{Tg}$ and $\mathrm{Td}$ of individual compounds. The blends of collagen and PVA was proposed to be partly miscible. The properties of Collagen/PVP were studied by Sionkowska [180]. 0.4 M acetic acid was used to dissolve collagen and PVP. The blends at Col/PVP weight ratios of 20/80-80/20 were demonstrated to be miscible $([\eta] \exp m$ $\left.>\left[\begin{array}{lll}\eta & i & m\end{array}\right]\right)$. The first peak $\left(\mathrm{T}_{1}\right)$ of DSC for collagen/PVP film $\left(87^{\circ} \mathrm{C}\right)$ at ratio of $50 / 50$ was higher than that of the single components (collagen was $80^{\circ} \mathrm{C}$ and PVP was $82^{\circ} \mathrm{C}$ ), where $T_{1}$ attributed to unfolding of triple helix for collagen and the single glass transition temperature for PVP respectively. The strong hydrogen bonds were formed between the carbonyl groups of the pyrrolidone rings in PVP and the hydroxyl and/or amino groups of collagen, which caused the collagen and PVP to be miscible. Additionally, the diameter of collagen fibrils in PVA film was larger than that in PVP at the same condition, as shown in Fig. 7. The weak interaction between collagen and PVA resulted in partially miscible, which did not disturb in collagen fibril formation. The strong interaction between collagen and PVP hampered the collagen molecules to form fibrils [181]. The thermal stability of Col/ PEG sponge was studied by Xue et al. [182]. 1\% collagen solution ( $5 \mathrm{~mol} / \mathrm{L}$ acetic acid) was added with PEG-20000 of different concentrations and then lyophilized. Td of the native collagen was $68.5^{\circ} \mathrm{C}$ and $\mathrm{Tg}$ of PEG was $67.5^{\circ} \mathrm{C}$. The $\mathrm{Td}$ values of Col/PEG films were first decreased to $59.7^{\circ} \mathrm{C}\left(10 \%\right.$ PEG) and then increased to $65.1^{\circ} \mathrm{C}(50 \%$ PEG). The decrease of thermal stability was also observed in the blends of collagen and PLGA [183]. Collagen and PLGA were dissolved in 1,1,1,3,3,3-hexafluoro-2-propanol (HFP). The blends were obtained with different Col/PLGA ratios of 50/50, 35/65 and 20/80 and then used for spinning. $\mathrm{Td}$ of the native collagen was about $80^{\circ} \mathrm{C}$ and $\mathrm{Tg}$ of PLGA was $42^{\circ} \mathrm{C}$. The Td values of complex decreased with the increase of the PLGA content. The blends were suggested to be immiscible due to the appearance of two distinct peaks of DSC curves.

Other biocompatibility polymers have also been used to blend with collagen for biomedical applications. The complex materials are usually manufactured into the 


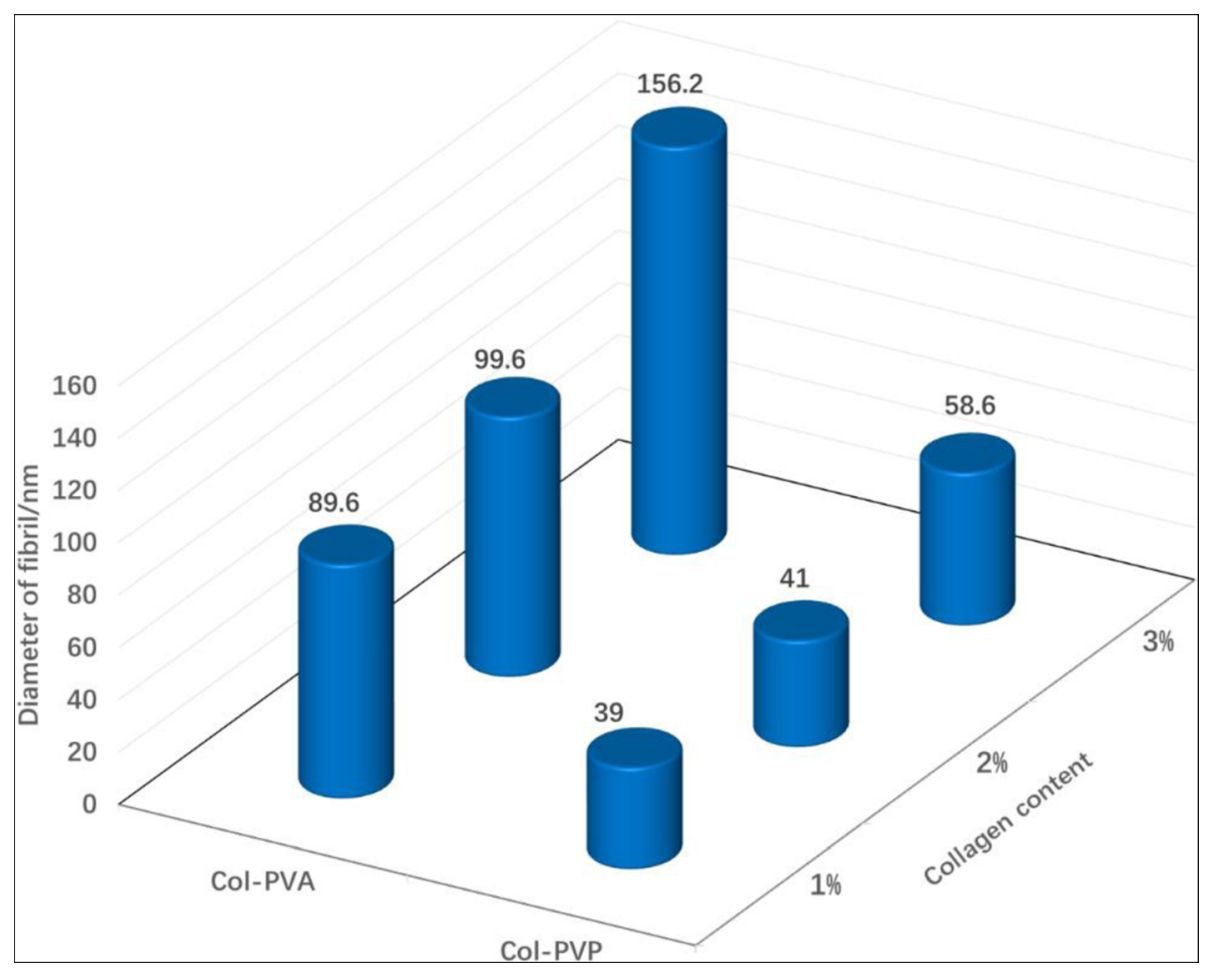

Fig. 7 Diameter of collagen fibrils in PVA (Col-PVA) and PVP (Col-PVP) films containing 1\%, 3\% and 5\% of collagen respectively [181]

form of hydrogel, film and scaffold which have much higher thermal stability due to loss of free water. Mechanical and biological properties of the blends have always been taken a major concern. The ratio of collagen to polymer would affect the physicochemical properties of the blends and should adapt to practical demand.

\section{The effect of crosslinking on thermal stability}

Crosslinking as the best effective method is generally used to promote collagen's thermal stability, mechanical property and resistance to enzymatic degradation. A crosslinking could be defined as the induction by physical or chemical method to connect the functional groups within one collagen chain to that in another chain. Herein, on the view of thermal stability, the physical and chemical crosslinking of collagen are summarized.

\subsection{Physical crosslinking}

Physical crosslinking is accepted as a safe, cheap and simple modification owing to no additional chemical reagents. Dehydrathermal (DHT) treatment, ultraviolet (UV) irradiation and ionizing radiation (gamma-ray and electron beam) are generally used.

DHT treatment is a commonly recommended approach of physical crosslinking, which is performed on heating dry collagen matrix under vacuum to around $100^{\circ} \mathrm{C}$ for $24-72 \mathrm{~h}$. During DHT process, the formation of the amide bonds between amine and carboxyl groups of collagen as well as the formation of the lysino-alanine bonds between the dehydro-alanine (produced by $\beta$ elimination of serine residues) and lysine residues in collagen chains cause intra- and inter-molecular crosslinks, as shown in Scheme 2 [184]. An appropriate DHT treatment is positive to thermal stability of collagen. The spinning collagen fibers were dried under tension at room temperature for $16 \mathrm{~h}$ and then heated in a vacuum oven at $110^{\circ} \mathrm{C}$ for $72 \mathrm{~h}$. The shrinkage temperature of bovine skin collagen fibers after DHT treatment increased by $12^{\circ} \mathrm{C}$ comparing with the uncrosslinked fibers, as reported by Weadock et al. [185]. The thermal stability of the porcine acellular dermal matrix scaffolds was also improved after DHT treatment [186]. The scaffold was obtained after lyophilizing the porcine skin which was removed the non-collagenous substances. The residual water continued to be removed at $40^{\circ} \mathrm{C}$, 0.05 bar for $6 \mathrm{~h}$. Crosslinking was carried out at $110^{\circ} \mathrm{C}$ for1 $2 \mathrm{~h}$. The $\mathrm{Td}$ values of the crosslinked scaffold was $6^{\circ} \mathrm{C}$ higher than that of uncross-linked scaffold. The thermal stability of fish skin collagen film was not insignificantly improved after DHT treatment. $0.5 \%$ silver carp collagen solution was air-dried under a laminar airflow at room temperature. Td of the crosslinked film after heating at $105^{\circ} \mathrm{C}$ for $24 \mathrm{~h}$ under vacuum $(0.05 \mathrm{Bar})$ was merely $3^{\circ} \mathrm{C}$ higher than that of non-crosslinked film [187]. Gorham and Light [184] found thermal degradation would take place as the heating temperature 


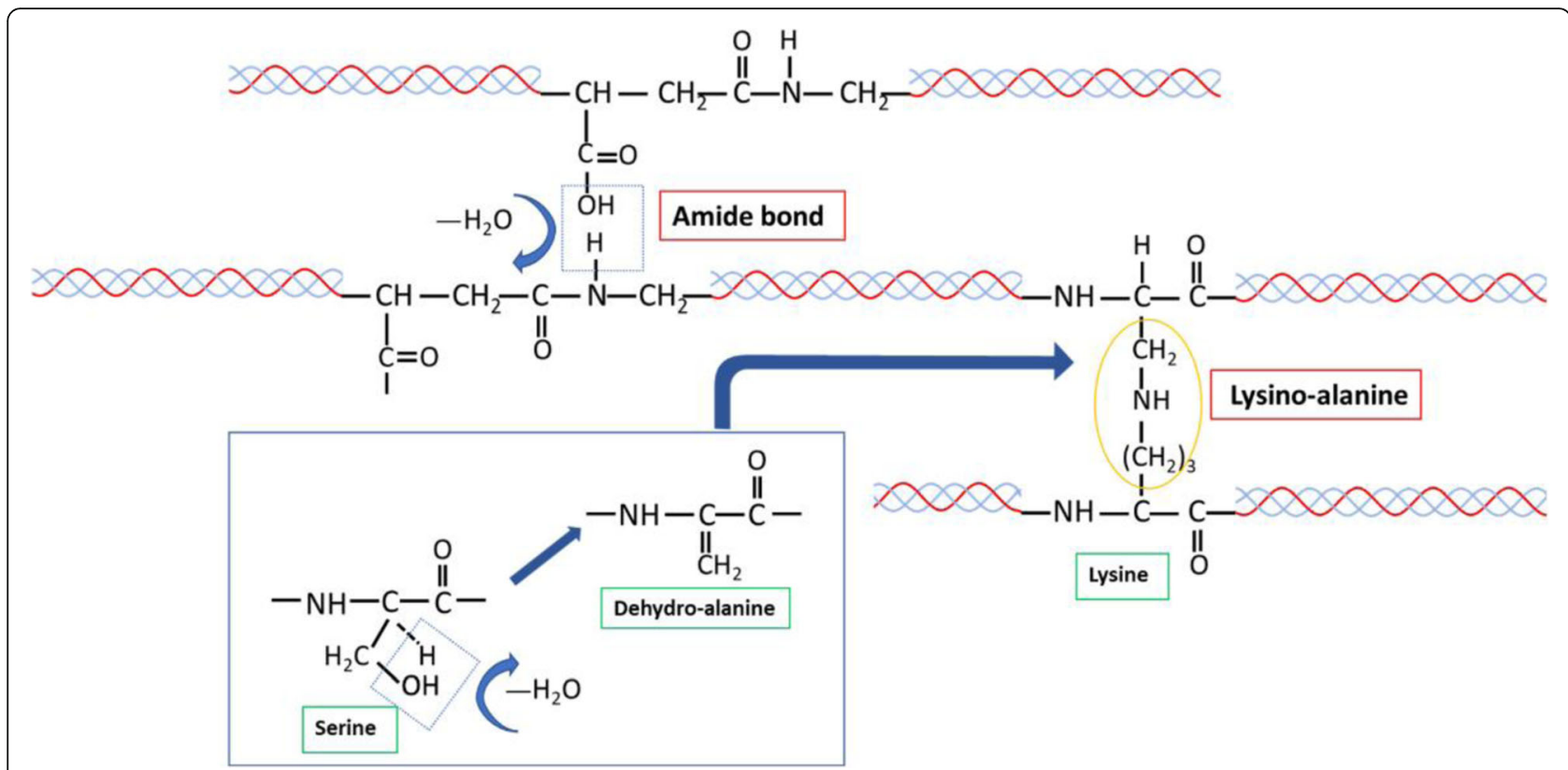

Scheme 2 The formation of amide bond and lysino-alanine during DHT treatment [184]

increased. $0.3 \%$ collagen solution (1-2 years old bovine skin) was lyophilized and then heated at different temperatures for $24 \mathrm{~h}$ under a vacuum of $11 \mathrm{mbar}$. Td of the collagen without heat treatment was $66.3^{\circ} \mathrm{C}$. The $\mathrm{Td}$ values of crosslinked collagen increased to $66.2^{\circ} \mathrm{C}$ as the heating temperature was $60^{\circ} \mathrm{C}$ and then decreased as the heating temperature further increased. The characteristic $\alpha 1, \alpha 2$ and $\beta$ chains of native collagen were observed in SDS-PAGE to be degraded into low molecular peptides as the heating temperature was $120^{\circ} \mathrm{C}$. However, the lysino-alanine bonds (crosslink bonds) increased as the heating temperature rose. The crosslinking and denaturation occur simultaneously during DHT treatment. The parameters of DHT treatment should be adjusted according to the different sources of collagen and the state of samples. Dehydration and drying of collagen samples are necessary prior to DHT treatment to prevent degradation under the high temperature. The thermal stability of collagen would significantly increase with the decrease of intra-fibrillar water content in collagen. Schroepfer and Meyer [188] determined the denaturation temperature of bovine hide at varying humidity by DSC. The humidity was adjusted by placing a small piece of hide under saturated water vapor or in a desiccator or by directly adding water. The Td values of hide decreased from about $180^{\circ} \mathrm{C}$ at water content of $3.7 \%$ to about $60^{\circ} \mathrm{C}$ at water content of $44 \%$. Td would not decrease as a water content was above $44 \%$ at which the collagen fibers were fully hydrated. The thermal stability of collagen could be improved by dehydration drying. Shen et al. [189] prepared a high thermal stability fish (southern catfish) collagen gel through the dehydration of ethanol. Collagen solution $(5 \mathrm{mg} / \mathrm{ml})$ was incubated at $30^{\circ} \mathrm{C}$ for $5 \mathrm{~h}$ as a control. The improved gels were obtained after being immersed in different concentrations of ethanol solutions (20-100\%) for $24 \mathrm{~h}$ at collagen/ethanol ratio of $1 / 10(\mathrm{w} / \mathrm{v})$. $\mathrm{Td}$ of the gels slowly increased from $43.1^{\circ} \mathrm{C}$ (control) to $49.2^{\circ} \mathrm{C}$ (60\% ethanol) and then evidently increased to $60^{\circ} \mathrm{C}$ ( $80 \%$ ethanol). Td of the gel could reach to $75.8^{\circ} \mathrm{C}$ in $100 \%$ ethanol solution.

UV irradiation as a non-ionizing irradiation could induce the amino acids residues (such as Trp, Phe and Tyr) of collagen to generate free radical to cause intermolecular crosslinks. Sinokowska and his group [190, 191] investigated the effect of sample state and UV irradiation time on the thermal stability of collagen. Three forms of collagen were prepared using RTT collagen. Tendon pieces were obtained from rat tail and then dried at $35^{\circ} \mathrm{C}$. Collagen solution was prepared by dissolving tendon fibers into $0.04 \mathrm{M}$ acetic acid. Collagen film $(0.015 \mathrm{~mm})$ were obtained by air-drying the collagen solution at $35^{\circ} \mathrm{C}$. The samples were irradiated at room temperature for different duration time. $\mathrm{Td}$ of the solution was determined by viscosity measurements and $\mathrm{Td}$ of pieces and film were determined by DSC. Td of the native solution, tendon piece and film were 40.2, 101.9 and $110.2^{\circ} \mathrm{C}$ respectively. The $\mathrm{Td}$ values of samples decreased as the irradiation time lengthened. After irradiating $2 \mathrm{~h}$, Td of the solution could not be determined due to completely denaturation. The $\mathrm{Td}$ values of piece and film decreased by $16.3^{\circ} \mathrm{C}$ and $4.3^{\circ} \mathrm{C}$ respectively [190]. The effect of irradiation on the thermal stability of RTT 
fibers in aqueous was also studied, which was carried out through immersing the RTT fibers in water and then irradiating at room temperature under air atmosphere for varying time. $\mathrm{Td}$ increased from $64.1^{\circ} \mathrm{C}$ to $67^{\circ} \mathrm{C}$ after irradiating for $0-3 \mathrm{~h}$ and then deceased from $57^{\circ} \mathrm{C}$ to $39.3^{\circ} \mathrm{C}$ after irradiating time was lengthened from 20 to $66 \mathrm{~h}$ [191]. The thermal stability of collagen crosslinked using UV irradiation was depended on the hydration degree of sample and the dosage of incident radiation (= intensity $\times$ time).

Exposure of collagen to ionizing irradiation such as gamma ray and electron beams is the other way to crosslink collagen through free radical mediation. Usually, hydroxyl radicals generated by the amino acid residues such as Phe, His and Met residues in collagen after absorbing irradiation form intermolecular crosslinks [192]. Tyrosine residues is also proposed as a crosslinking point. Crosslinking is carried out by bonding two tyrosyl radicals to form dityrosine bonds [193]. Inoue et al. [194] prepared collagen gels by directly irradiating collagen solution in acidic condition using gamma-rays. Type I collagen of porcine was dissolved into solution at $\mathrm{pH} 3.0$ to obtain acid collagen solution $(0.3 \%)$. The acidic gels were obtained after irradiating with gammarays of different doses of 0-31 kGy (dose rate 15$16 \mathrm{kGy} / \mathrm{h}$ ) at room temperature in air. Neutral collagen solution was obtained by adjusting the $\mathrm{pH}$ value with PBS ( $\mathrm{pH} 7.4$ ) and then incubated at $37^{\circ} \mathrm{C}$ for $30 \mathrm{~min}$. The neutral gels were irradiated at same condition as acidic gels. Acidic gels were transparent and highly shrank while neutral gels kept original state as the irradiation dose increased. Crosslinking rather than degradation was proposed to occur in acidic gels under the low dose of gamma-rays irradiation (1.4 and $2.1 \mathrm{kGy}$ ), because the $\alpha 1$ and $\alpha 2$ chains of the acidic gels molecules shifted to a higher molecular weight and there were not any fragmented collagen with lower molecular weight observed in SDS-PAGE. Acidic gels were gradually degraded as the irradiation dose further increased. Collagen gels prepared in aqueous solution by gammairradiation were studied by Zhang et al. [195]. 1.54\% type I collagen solution (RTT, Beijing Kelaode, pH6.2) was directly irradiated with different dose (dose rate was 20 $\mathrm{kGy} / \mathrm{min}$ ) at room temperature to form collagen gels. The collagen gels were transparent and kept almost same size as irradiation doses were 10-20 kGy. The Td values of collagen gels irradiated with gamma-rays were higher than that of un-irradiated gel $\left(66.4^{\circ} \mathrm{C}\right)$, which were 83.5 (5 kGy), 73.6 (10 kGy), 71.7 (15 kGy), 81.1 (20 $\mathrm{kGy}$ ) and $89.8^{\circ} \mathrm{C}$ (25 kGy) respectively. Jiang et al. [196] used electron beams to modified calfskin collagen membrane which was obtained by drying self-assemble collagen fibers. The membranes were irradiated by electron beams at low temperature in nitrogen atmosphere with different irradiation dose or without. The hydrothermal and xerothermic shrinkage temperature of the samples were determined by micro-shrinkage tester. The shrinkage temperature of the membranes increased with the increase of the irradiation dose and were about $15^{\circ} \mathrm{C}(100$ $\mathrm{kGy}$ ) higher than that of the un-irradiated membrane.

Obviously, physical crosslinking is affected by the state of sample, temperature, radiation dose, $\mathrm{pH}$ value and atmosphere condition. Crosslinking induced by physical method is always together with degradation which should be prevented by fine tuning of physical processes.

\subsection{Chemical crosslinking}

Chrome, plant tannin and aldehyde have been wildly used in tannage to obtain leathers of various desirable properties such as high hydrothermal stability, favourable biological inertness and excellent mechanical property. Nowadays, more chemical regents have been used to crosslink native collagen or collagenous materials for versatile applications. Chemical crosslinking is carried out via introducing functional groups into collagen molecules. Metal complex compounds, which are mainly applied to tannage for leather industry, stabilize collagen by forming coordinative bonds with the carboxylate groups of collagen chains. Plant polyphenols, as one of the commonly tanning agents as well as a crosslinker, crosslink collagen mainly through forming multipoint hydrogen bonds. Most of other chemical reagents crosslink collagen through different crosslinked mechanisms, which are mainly involved in the $\varepsilon$-amino groups of collagen.

\subsubsection{Metal complex compounds}

Metal complex compounds crosslink collagen through coordinating with the carboxylate groups of collagen. Chromium (III) as the most commonly used tanning agent could remarkably improve the hydrothermal stability and chemical properties of leather. Ts of chrome-tanned leather could easily achieve to $110^{\circ} \mathrm{C}$ or higher. At least two carboxylate groups of collagen replace ligands (mainly water) of the polynuclear chrome complex to form stable coordination bonds, as shown in Scheme 3a [197]. At the same condition, the Ts values of the leathers tanned with chrome, zirconium and aluminum were 102,83 and $72^{\circ} \mathrm{C}$ respectively [199]. Chromium is not suitable to crosslink collagen for other applications, because chromium is cytotoxic and might turn into hexavalent chromium of highly toxic. Zirconium, which is only second to chromium to promote the hydrothermal stability of leather, has good biocompatibility and low toxicity [200]. Therefore, zirconium is a candidate crosslinker to improve the properties of collagenous materials used in biomedicine. Zirconium is easily hydrolyzed and only stable at a low $\mathrm{pH}(<3)$. Masking agents are usually added to modified the properties of zirconium complex. Liu et al. [201] used zirconium 


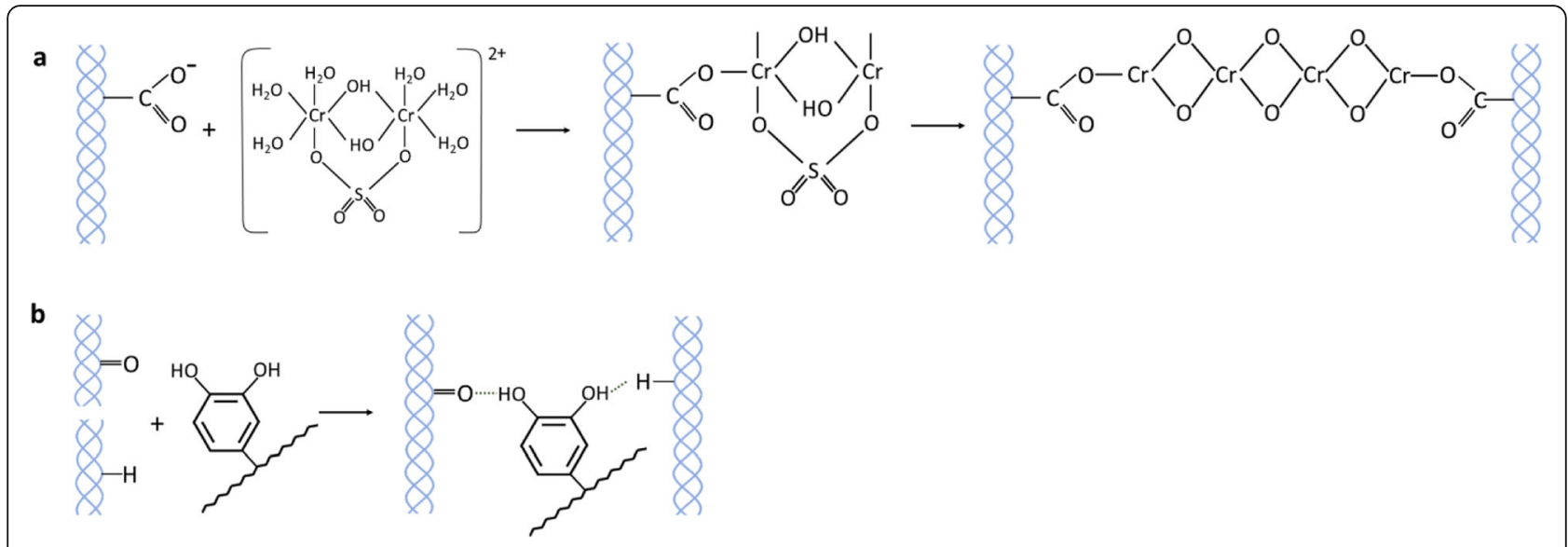

Scheme 3 Schematic illustration showing the reaction of chromium (a) [197] and plant polyphenols (b) with collagen respectively [198]

complex modified by sodium citrate to crosslink calfskin collagen sponge which was obtained after lyophilizing collagen solution. Taking the denaturation temperature (by DSC) as the index, the optimal crosslinked condition was carried out: the molar ratio of sodium citrate/ zirconium (IV) was 0.18 , crosslinked time was $2 \mathrm{~h}$, the concentration of sponge in complex solution was $0.01 \mathrm{~mol} / \mathrm{L}$, temperature was $37^{\circ} \mathrm{C}$. $\mathrm{Td}$ of the crosslinked sponge was $36.5^{\circ} \mathrm{C}$ higher than that of the uncross-linked sponge.

\subsubsection{Plant polyphenols}

Plant polyphenols, also known as vegetable tannins, were firstly applied in leather industry. As a biomaterial, plant polyphenols have been used to modify collagen for more extensive applications. Multipoint hydrogen bonds could be formed between phenolic hydroxyl groups of polyphenols and hydroxyl, carboxyl, amino or amide groups of collagen chains, as shown in Scheme 3b [198]. He et al. [202] used procyanidin to crosslink collagen in solution. Collagen solution and procyanidin solution were mixed at different procyanidin/collagen ratios of $0-8 \%$ $(\mathrm{w} / \mathrm{w})$ at $\mathrm{pH}$ 3.0. The collagen concentration was kept at $2.5 \mathrm{mg} / \mathrm{ml}$. Then the crosslinked mixtures were dried at room temperature for 1 week. $\mathrm{Td}$ of the native collagen films was $65.5^{\circ} \mathrm{C}$ and melting temperature of procyanidin was $70.0^{\circ} \mathrm{C}$. The $\mathrm{Td}$ values of crosslinked films first increased and then decreased. Td of the film at procyanidin content of $4 \%$ was the highest $\left(83.3^{\circ} \mathrm{C}\right)$ and then reduced to $74.3^{\circ} \mathrm{C}$ as procyanidin content was $8 \%$. Madhan et al. [203] crosslinked RTT fibers through soaking the RTT fibers obtained after the removal of noncollagenous substances into the catechin solutions of different concentrations at $27^{\circ} \mathrm{C}$ for $27 \mathrm{~h}$. The hydrothermal stability of the samples was determined by microshrinkage tester. The Ts values of the crosslinked fibers increased with the increase of catechin concentration and increased by $9^{\circ} \mathrm{C}$ as $20 \mathrm{mM}$ catechin was added.
Catechin with crosslinking effect was also used as natural dyestuff to dye collagen membrane [204]. Catechin contains a large number of benzene rings and phenolic hydroxyl groups which are easily oxidized to form quinonoid chromophoric groups and also easily form conjugated fused rings to make polyphenols appear color. The best properties of membrane could be obtained after agitating in $2 \%$ catechin for $3 \mathrm{~h}$ at $40^{\circ} \mathrm{C}(\mathrm{pH} 4)$. Td of the membrane was $18^{\circ} \mathrm{C}$ higher than that of the native collagen membrane and the tensile strength of the membrane increased by $1.26 \mathrm{MPa}$ after being crosslinked.

\subsubsection{Other crosslinkers}

The functional groups of most crosslinkers such as aldehydes, genipin, multifunctional epoxy compounds and N-hydroxysuccinimide (NHS)/Polycarboxylic acids could directly react with free amino groups within different collagen chains to form crosslinking. The crosslinking induced by 1-ethyl-3(3-dimethylaminopropyl)-carbodiimide (EDC) and diphenylphosphorylazide (DPPA) begins with the activation of the carboxyl groups in collagen chains to promote the formation of amido bonds between adjacent carboxyl and amine groups of collagen. Transglutaminase (TGase) catalyzes an acyltransfer reaction mainly involved in glutamine and lysine residues of collagen.

Aldehydes crosslink collagen via forming Schiff bases between the $\varepsilon$-amino groups of lysine or hydroxylysine residues and the aldehyde groups of aldehydes, as shown in Scheme 4a. Glutaraldehyde (GTA) as a typical crosslinker could remarkably enhance the thermal stability of collagen. Different states of collagen crosslinked using GTA have been investigated. 1g dermal layer, which was obtained after removing non-collagenous substances of sheepskin, was crosslinked in $100 \mathrm{ml}$ 0.5\% GTA solution for $1 \mathrm{~h}$ at room temperature ( $\mathrm{pH}$ 7.4). The Ts values of the crosslinked and the uncross-linked dermal layers 
a

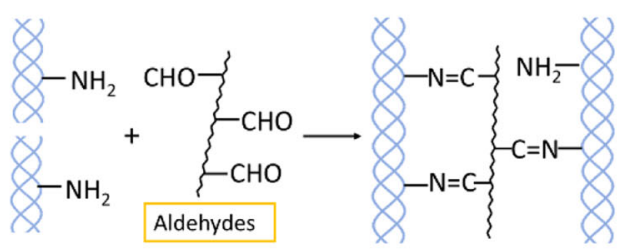

b

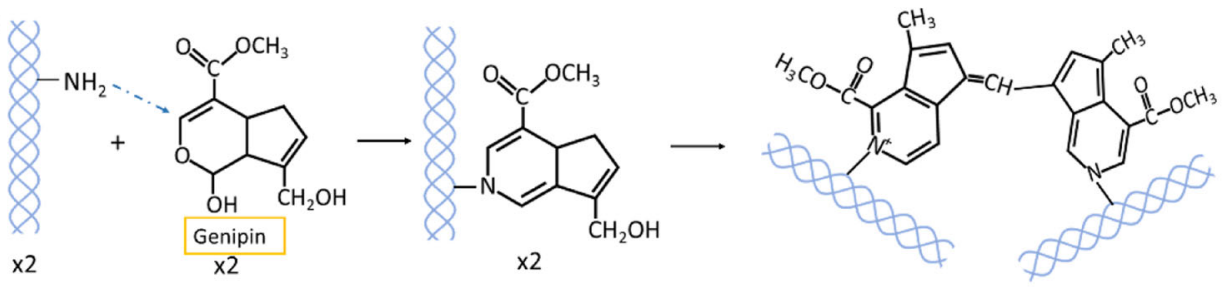

C

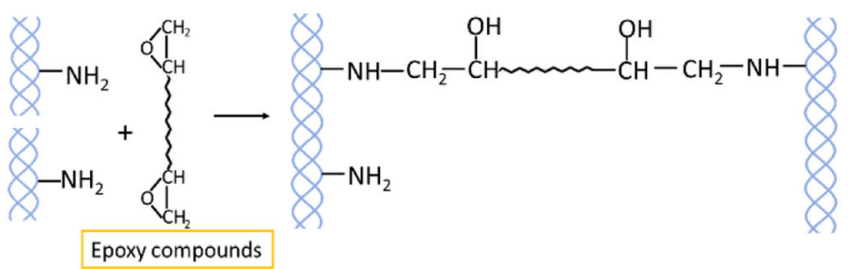

d

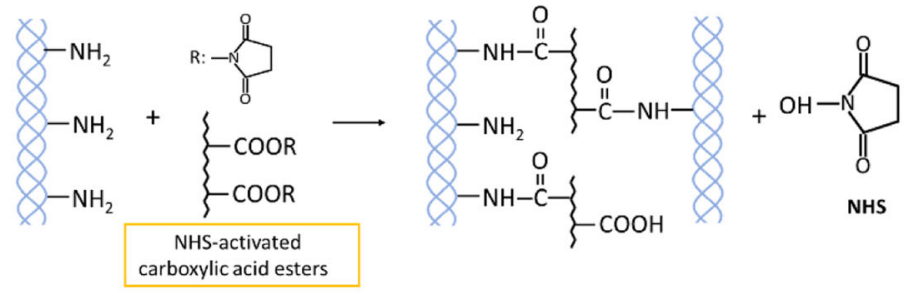

e

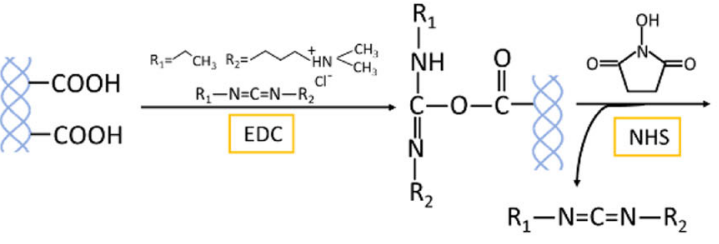<smiles>NNCCCCC(=O)ON1C(=O)CCC1=O</smiles>

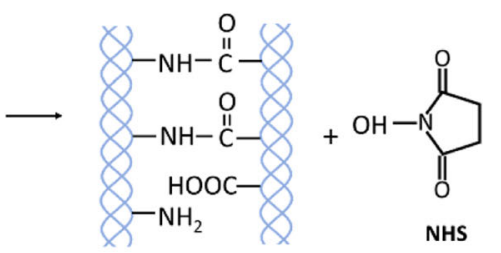

f

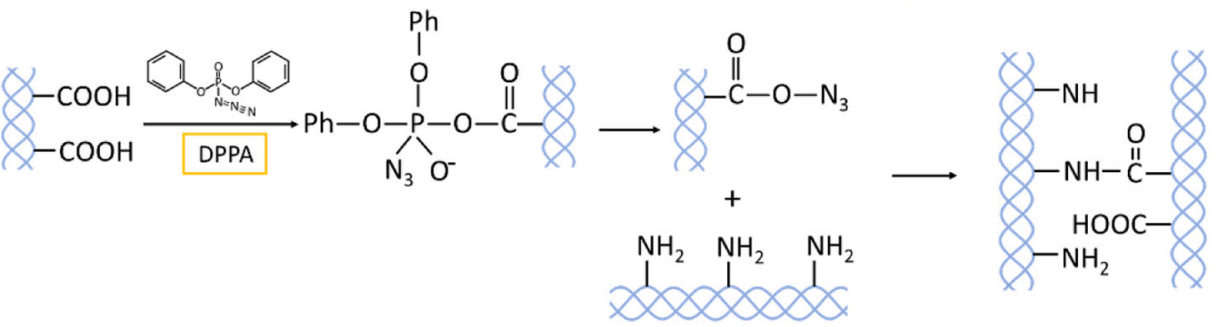

g

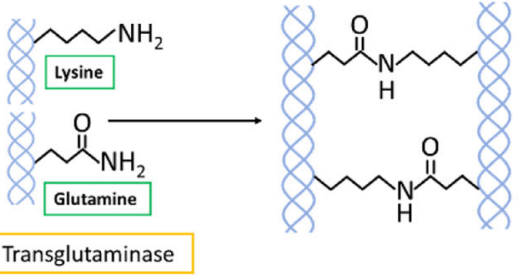

Scheme 4 Crosslinking mechanisms of collagen with Aldehydes (a) [205], Genipin (b) [206], Epoxy compounds (c) [207], NHS-activated carboxylic acid esters (d) [208], EDC/NHS (e) [209], DPPA (f) [210] and Transglutaminase (g) [211] respectively 
were 78 and $56^{\circ} \mathrm{C}$ respectively [212]. Calfskin collagen solutions were crosslinked using GTA at different GTA/ collagen ratios $(\mathrm{w} / \mathrm{w})$ for $24 \mathrm{~h}$ at room temperature $(\mathrm{pH}$ 4.0). The $\mathrm{Td}$ values of the uncross-linked collagen were $39.7^{\circ} \mathrm{C}$ and that of crosslinked solution using $1 \%$ GTA was $40.3^{\circ} \mathrm{C}$. The thermal stability of the collagens and the degree of crosslinking tended to flatten out as GTA content further increased [213]. Collagen gels were prepared by incubating the collagen solutions (PBS, 100 $\mathrm{mmol} / \mathrm{L} \mathrm{NaCl}, \mathrm{pH} 7.4$ ) at $37^{\circ} \mathrm{C}$ for $3 \mathrm{~h}$, and then crosslinked using GTA at different molar ratios of [CHO]/ $\left[\mathrm{NH}_{2}\right]$ where $\mathrm{CHO}$ was aldehyde groups of GTA and $\mathrm{NH}_{2}$ was $\mathcal{E}$ - amino groups of lysine or hydroxylysine residues. $\mathrm{Td}$ of the uncross-linked gel was $47.1^{\circ} \mathrm{C}$. The $\mathrm{Td}$ values observably increased to $63.9^{\circ} \mathrm{C}$ as $[\mathrm{CHO}] /\left[\mathrm{NH}_{2}\right]$ was 0.6 and then levelled off as $[\mathrm{CHO}] /\left[\mathrm{NH}_{2}\right]$ was above 3 [214]. The improvement of thermal stability was significantly obtained when low dosage of GTA was added. The majority of reactive amino groups in collagen could form intra- and inter-molecular multipoint crosslinks with aldehyde groups of GTA. The thermal stability of collagen levels off due to the formation of single-point bonding as the dosage of GTA is over high [212]. Despite GTA-treated materials such as bioprosthesis valves and grafts have been applied to clinical, an undesirable side-effect of toxicity is an issue. Recently, dialdehyde compounds derived from natural biomass with good biodegradability and low toxicity have attracted increasing attention. The thermal stability of collagen have been demonstrated to be improved by dialdehyde compounds such as oxidized glycogen, oxidized chitosan oligosaccharide, dialdehyde cellulose, oxidized sodium alginate and dialdehyde carboxymethyl cellulose (DCMC) [215218]. A collagen cryogel was prepared by Tan et al. [219] using dialdehyde carboxymethyl cellulose to crosslink collagen in solution at different $\mathrm{DCMC} / \mathrm{Col}$ weight ratios of $0.0-0.2 \%$ with constant collagen concentration of $5 \mathrm{mg} / \mathrm{ml}$. Td of the cryogels increased by $22^{\circ} \mathrm{C}$ at ratio of $0.1 \%$, and then decreased slightly at ratio of $0.2 \%$ where insoluble complexes were found. The complex solution of collagen and the dialdehydes might be not stable enough due to large molecular weight as well as the strong electrostatic attraction between collagen and the dialdehydes. A more stable hydrogel of collagen and DCMC with a higher concentration was prepared by Yang et al. [205] using the biphasic acetic acid/1-ethyl3methylimidazolim acetate solvent system. The Col/ DCMC solution with constant DCMC content contained different collagen concentrations of $5-25 \mathrm{mg} / \mathrm{ml}$. The $\mathrm{Td}$ values exhibited a linearly upward tendency with the increase of collagen content. The gels of all the collagen concentrations were transparent and homogenous.

Genipin is an iridoid derivative. The C-atom of genipin is firstly under a nucleophilic attack from primary amine groups of amino acids residues (Lys, Hyl, Arg), and then tertiary nitrogen of collagen embeds into the sixmembered ring of genipin to replace an oxygen atom, finally a nitrogen-iridoid could be formed. Subsequently, two iridoids are linked via a radical reaction to form intra- and inter-molecular crosslinks (Scheme 4b) [206]. The report of fixing bovine pericardium using genipin came from Sung et al. [220]. The bovine pericardium was soaked in $0.625 \%$ genipin solution for 3 days at room temperature ( $\mathrm{pH}$ 7.4). Ts of the fixed pericardium increased by about $13^{\circ} \mathrm{C}$ comparing with the unfixed pericardium $\left(63.9^{\circ} \mathrm{C}\right)$. Storage stability of genipincrosslinked and GTA-crosslinked collagen was reported by Sung et al. [221]. Porcine pericardia prepared by removing non-collagenous substances was fixed using $0.625 \%$ genipin or GTA in buffer solution $(\mathrm{pH} 7.4)$ at $37^{\circ} \mathrm{C}$ for 3 days. The samples were stored in a sterilized water after sterilizing. The $\mathrm{Td}$ values of GTA-fixed pericardia was $86.5^{\circ} \mathrm{C}$ and then began to decrease at 3 months after storage. $\mathrm{Td}$ of genipin-fixed pericardia was $80.5^{\circ} \mathrm{C}$ and kept constant until 6 months after storage. Additionally, no apparent cytotoxicity was observed for both the genipin-fixed tissue and storage solution during storage process when compared to GTA-fixed tissue.

Multifunctional epoxy compounds have strong reactivity due to three-membered cyclic ether groups. Epoxy groups of epoxy compounds could form multipoint crosslinking among collagen molecules with the $\varepsilon$-amino groups of lysyl residues in collagen at alkali condition (Scheme 4c) [207, 222]. The crosslinking between collagen and epoxy compounds have been demonstrated to be remarkably affected by $\mathrm{pH}$ [222]. $1 \mathrm{~g}$ sheep dermal collagen prepared by removing non-collagenous substances was immersed in $100 \mathrm{~mL}$ buffered solution containing 4 wt\% 1,4-butanediol diglycidyl ether at the different $\mathrm{pH}$ values of $4-12\left(20^{\circ} \mathrm{C}\right)$. At $\mathrm{pH} 7$, Ts of the crosslinked collagen showed the least increase comparing with the crosslinked collagens under other $\mathrm{pH}$ values. Under acid condition ( $\mathrm{pH}<7)$, amine group content of collagen kept constant and Ts slightly increased with the decrease of the $\mathrm{pH}$ values. At $\mathrm{pH}=8-10$, Ts exhibited a lineal upward tendency accompanying with the evidently decease of amine group contents. At a higher $\mathrm{pH}(>10)$, both Ts and amin group content were kept constant. Additionally, Ts of the crosslinked collagen in alkali condition were always much higher than that in acid condition. Shen et al. [223] pointed out the glycerol polyglycidyl ether exhibited good uniform distribution of crosslink density throughout the porcine aortic valves. Porcine aortic valves were immerged in $4 \%$ glycerol polyglycidyl ether solution for 6 days at room temperature. Hydrothermal stability of distinct layers (outer, middle, inner and entire wall as well as leaflet) in 
aortic valves was almost same and was $20^{\circ} \mathrm{C}$ higher than that of the uncross-linked aortic valve.

The carboxyl groups of polycarboxylic acids are turned into an active ester groups by NHS under the action of EDC or 1,3-dicyclohexylcarbodiimide catalyst. Crosslinking would be formed between the active ester groups and the amino groups of collagen molecules, thus enhancing the thermal stability of collagen (Scheme $4 \mathrm{~d}$ ). Citric acid, adipic acid, gallic acid, poly ( $\gamma$-glutamic acid) and poly $(\alpha, \beta$-malic acid) have been chosen into system of NHS-activated carboxylic acid esters [208, 224-230]. The properties of collagen crosslinked using NHS activated adipic acid (NHS-AA) were studied by Li and her group [208, 224-227]. Alkali-solubilized collagen of bovine hide and PSC of fish skin were dissolved in phosphate solution buffer $(\mathrm{pH}$ 6.3) to make collagen concentration at $0.3 \%(\mathrm{w} / \mathrm{w})$. Two collagen solutions were mixed with NHS-AA of different concentrations. $\mathrm{Td}$ of the alkali-solubilized collagen reached to the highest $\left(40.8^{\circ} \mathrm{C}\right)$ at NHS-AA concentration of $1.5 \mathrm{mM}$, which was $4.2^{\circ} \mathrm{C}$ higher than that of the uncross-linked collagen. Td of PSC increased by $13.3^{\circ} \mathrm{C}$ at NHS-AA concentration of $1.05 \mathrm{mM}$ comparing with the native collagen [208, 224]. The decrease of amino groups in alkalisolubilized collagen due to the deamination of Asn and Gln into Asp and Glu caused less crosslinks than in PSC. The collagen self-aggregation was observed to be affected with the increase of NHS-AA. Calfskin collagen solution was crosslinked using NHS-AA of different concentrations at $\mathrm{pH} 7.2$ and then heated from $4^{\circ} \mathrm{C}$ to 37,39 and $41^{\circ} \mathrm{C}$ within $1 \mathrm{~min}$ to form fibrils. Concentrations of NHS-AA were converted to molar rations of $[\mathrm{NHS}-\mathrm{AA}] /\left[\mathrm{NH}_{2}\right]$ where [NHS-AA] was active ester groups and $\left[\mathrm{NH}_{2}\right]$ was $\varepsilon$-amino of lysine and hydroxylysine residues. The turbidity and the rate of fibril formation decreased as the NHS-AA increased, especially at a $[\mathrm{NHS}-\mathrm{AA}] /\left[\mathrm{NH}_{2}\right]>0.6 / 1$. The self-aggregation was still carried out at a [NHS-AA] $/\left[\mathrm{NH}_{2}\right]$ ration $<0.3 / 1$ when temperature was below $39^{\circ} \mathrm{C}$ [225]. The properties of collagen gels (fish skin) prepared by incubating the complex solutions ( $\mathrm{pH}$ 7.4) of collagen and NHS-AA at $30^{\circ} \mathrm{C}$ for $5 \mathrm{~h}$ were further studied. The gels became transparent as [NHS-AA]/[NH2] was above 0.2 . The degree of crosslink observably increased with the increase of NHS-AA and then leveled off at a [NHS-AA]/[NH2] ratio $>0.8$. $\mathrm{Td}$ of the gel increased by $7.9^{\circ} \mathrm{C}$ at ratio of 1.6 comparing with the uncross-linked gel [226]. Different thermal stability of collagen gels was revealed by changing the order of adding NHS-AA. The collagen gels (calfskin) were crosslinked using NHS-AA of the same dosage before the self-aggregation (CBF), simultaneously with and after the self-aggregation (CSF and CAF) respectively. The thermal stability of the gels exhibited in order of CAF > CSF > CBF. The appearance of the gels was non- transparent for CAF and became transparent for CSF and $\mathrm{CBF}$ at a [NHS-AA] $\left[\mathrm{NH}_{2}\right]$ ratio > 0.6/1 [227]. Additionally, the isoelectric point of crosslinked collagen could be decreased via introducing extra carboxyl groups by NHS-activated carboxylic acid esters to made it possible to dissolve in the neutral water [228-230].

As "zero-length" crosslinker, EDC and DPPA promote the formation of amido bond between adjacent carboxylic and amino groups of collagen and don't stay in the systems $[209,210]$. The activated mechanisms of carboxylic groups of Glu and Asp residues induced by EDC and DPPA are different. EDC converts carboxyl groups of collagen into active $\mathrm{O}$-acylisourea groups, subsequently crosslinking takes place after nucleophilic attacking $\mathrm{O}$-acylisourea groups by free amine groups of lysine or hydroxylysine residues. Usually, during the EDC crosslinking procedure, NHS is added as a catalyst to significantly enhance the crosslinking efficiency owing to the formation of more stable active intermediates (Scheme 4e). The thermal stability of the collagen crosslinked using EDC and EDC/NHS respectively was compared in Old Damink's study [231]. 1g sheep dermal layers obtained after removing non-collagenous substances were immersed into $100 \mathrm{ml}$ aqueous solution containing $1.15 \mathrm{~g}$ EDC or $1.15 \mathrm{~g}$ EDC and $0.69 \mathrm{~g}$ NHS at room temperature for $4 \mathrm{~h}$. The $\mathrm{pH}$ value was kept at 5.5 during the reaction. Ts of the dermal layer treated with EDC increased by $17^{\circ} \mathrm{C}$ and that treated by EDC/NHS increased by $30^{\circ} \mathrm{C}$ comparing with the native dermal layer $\left(56^{\circ} \mathrm{C}\right)$. DPPA converts carboxyl groups into acylazide groups which further react with the amino groups of adjacent collagen chains (Scheme 4f). The thermal stability of the collagen treated with DPPA was significantly affected by the solvent used for DPPA [210]. Herbage and his group immersed $10 \mathrm{mg}$ dry pericardial samples into $5 \mathrm{ml}$ 1\% DPPA solution in different solvents at $4^{\circ} \mathrm{Cfor} 24 \mathrm{~h}$. $\mathrm{Td}$ of the untreated sample was $67.3^{\circ} \mathrm{C}$. The $\mathrm{Td}$ values of the samples treated with DPPA in dimethylformamide, acetone and dichloromethane were $81.9,72.4$ and $67.4^{\circ} \mathrm{C}$ respectively. The thermal stability of the collagen treated with DPPA (according to the above method) and GTA respectively was further compared. Collagen gel was obtained after complete swelling of calf dermis powder in acetic acid. Collagen sponge was obtained by lyophilizing the $0.7 \%$ collagen gel and film were prepared by drying $1.5 \%$ gel at room temperature for 3 days. The sponge and film were crosslinked using $1 \%$ GTA at $20^{\circ} \mathrm{C}$ and $\mathrm{pH} 6.2$ for $24 \mathrm{~h}$. The thermal stability of the DPPA-treated sponge and film increased by $20^{\circ} \mathrm{C}$ comparing with the untreated sponge and film. The $\mathrm{Td}$ values of GTA-treated sponge and film were 27 and $22^{\circ} \mathrm{C}$ higher than that of the uncross-linked sample, respectively [232]. At the optimal condition, the thermal stability of collagen could be significantly improved by DPPA. 
TGase-mediated crosslinking is a nontoxic method for stabilizing collagen and collagenous materials. As an enzyme in various organisms, TGases are involved in essential biological processes [211]. The $\gamma$-carboxamide groups of glutamine residues catalyzed by TGases are acyl donor and the $\mathcal{E}$-amino groups of lysine residues or primary amino groups act as acyl acceptor. Consequently, the intra-or inter- molecular crosslinks can be achieved via the formation of $\varepsilon$-( $\gamma$-glutamyl) lysine bonds (Scheme 4g) [233]. The thermal stability of the collagen treated with TGase was affected by the different states of collagen. An evident improvement of thermal stability of the TGase-treated collagen solution was reported by Chen et al. [234]. Porcine skin collagen solution $(10 \mathrm{mg} / \mathrm{ml})$ was added with TGase $(60 \mathrm{U} / \mathrm{g}$ collagen) or without and then incubated at $25^{\circ} \mathrm{C}$ and $\mathrm{pH}$ 4 for $12 \mathrm{~h}$. The sponges were obtained after lyophilizing the solutions. The $\mathrm{Td}$ values of the untreated and TGase-treated sponges were 114 and $177^{\circ} \mathrm{C}$ respectively. TGase showed not contribution to thermal stability of collagen fibers in Cheng's study [235]. $10 \mathrm{~g} / \mathrm{kg}$ collagen fiber suspensions prepared by removing non-collagenous substances from limed bovine skin were added with TGase $(20 \mathrm{U} / \mathrm{g}$ collagen) and then reacted at room temperature for $4 \mathrm{~h}$. Td of the TGase-treated collagen fibers was $82.95^{\circ} \mathrm{C}$ which was same as the native fibers $\left(82.58^{\circ} \mathrm{C}\right)$.

The thermal stability of collagen or collagenous materials could be significantly improved by crosslinking. Usually, the denaturation temperature of collagen as insoluble forms such as fibers, films and sponges are always much higher than that in solution. Therefore, physical crosslinking, which introduce strong energy into collagen, is more suitable for modification of dried collagen matrixes. The degree of chemical crosslinking would be affected by different states of collagen. The collagen molecules in solution are more scattered, which is not conducive to the formation of intermolecular crosslinks. For leather industry, the hydrothermal stability of leather is very important. The desirable properties of leather could be easily obtained by the use of chromium and GTA in spite of the toxic issue. Besides of thermal stability, the suitable physicochemical property and acceptable biocompatibility are also taken major concern when collagen is applied in biomedicine fields. The selection and combination of crosslinkers and crosslinking methods are necessary during practical processing.

\section{Conclusion}

Intact triple helical structure endows collagen excellent characteristics which is the premise for diversified applications. The native structure of collagen would collapse during heating process. The thermal stability is a macroscopic expression of collagen structure stability. The studies of thermal denaturation mechanism have been developed from traditional statistics to model simulation which could more accurately reveal the thermal denaturation behavior of collagen. Usually, collagen is extracted into aqueous solution for direct use or to be further manufactured into gel, fiber, membrane, sponge, scaffold and so on according to various applications. The stability of triple helix would be easily affected by the use of solvent and physical assisted means. The monitoring of thermal stability is necessary for helping to adjust the processing technology. Modification of collagen is carried out to promote thermal stability, mechanical property and resistance to enzymatic degradation. The demand of thermal stability varies with the different uses of collagenous materials. Hydrothermal stability is the most important standard for leather. However, for biomedical materials, good biocompatibility and low toxicity are also taken major concern. The choice of reagents and assisted means during processing and the use of modified methods should adapt to the demand of practical applications.

\section{Abbreviations}

ASC: Acid-soluble collagen; PSC: Pepsin-soluble collagen; Col: Collagen; AA: Acetic acid; Gly: Glycerol; RTT: Rat tail tendon; ILs: Ionic liquids; AMS: Diethyl methyl ammonium methane sulfonate; BCS: Bis-choline sulphate; IDP: 1-butyl-3-methyl imidazolium dimethyl phosphate; CDHP: Choline dihydrogen; [EMIM][CI]: 1-ethyl-methylimidazolium chloride; [EMIM][Br]: 1-ethyl-methylimidazolium bromide; [EMIM][AC]: 1-ethyl-3methylimidazolium acetate; [EMIM][BF $]$ : 1-ethylmethylimidazolium tetrafluoroborate; [EMIM] [N (CN) $)_{2}$ : 1-ethyl-methylimidazolium dicyanamide; [BMIM][CI]: 1-butyl-3-methylimidazolium chloride; [BMIM][BF4]: 1-butyl-3methylimidazolium tetrafluoroborate; AA/[EMIM][Ac]: Acetic acid/1-ethyl-3methylimidazolium acetate; CS: Chondroitin sulfate; C4S: Chondroitin 4sulfate; HA: Hyaluronic acid; HPMC: Hydroxypropyl methylcellulose; CMC: Carboxymethyl cellulose; CH: Chitosan; PVA: Poly-vinyl-alcohol; PVP: Poly-vinyl-pyrrolidone; PEG: Poly-ethylene-glycol; PLGA: Poly-D, L-lactideco-glycolide; HFP: 1,1,1,3,3,3-hexafluoro-2-propanol; GTA: Glutaraldehyde; DCMC: Dialdehyde carboxymethyl cellulose; NHS: N-hydroxysuccinimide; EDC: 1-ethyl-3(3-dimethylaminopropyl)-carbodiimide; NHS-AA: NHS activated adipic acid; DPPA: Diphenylphosphorylazide; TGase: Transglutaminase; Er: Specific dielectric constant; DHT: Dehydrathermal; UV: Ultraviolet; [ $\eta$ ] exp m: Specific viscosity; [ $\eta$ ] i m: Ideal intrinsic viscosity; PBS: Phosphate buffered saline; CD: Circular dichroism measurements; DSC: Differential scanning calorimetry; SDS-PAGE: Sodium dodecyl sulfate polyacrylamide gel electrophoresis; FTIR: Fourier transform-infrared

\section{Acknowledgements}

Not applicable.

\section{Authors' contributions}

GYL made substantial contributions to conception and design of this review, and critical revised the manuscript. XXZ wrote and revised the manuscript. SCX participated in the design of this review. LRS revised the draft from the language and logicality aspects. All authors read and approved the final manuscript.

\section{Funding}

The research is funded by the National Natural Science Foundation of China (Nos. 21776184 and 21606156).

Availability of data and materials

The datasets analyzed during the review are available in the references which have been specified in the article. 


\section{Competing interests}

The authors declare that they have no competing interests.

\section{Received: 7 May 2020 Accepted: 3 July 2020}

Published online: 05 August 2020

\section{References}

1. Li ZQ, Liao LL. The chemistry and histology of animal skins. China: China Leather Industry Press; 2010.

2. Avery NC, Bailey AJ. The effects of the Maillard reaction on the physical properties and cell interactions of collagen. Pathol Biol. 2006;54:387-95.

3. Gelse K. Collagens-structure, function, and biosynthesis. Adv Drug Deliv Rev. 2003;55:1531-46.

4. Jiang TD. Collagen and collagen protein. China: Chemical Industry Press; 2006

5. Ricard-Blum S. The collagen family. Cold Spring Harb Perspect Biol. 2010;3:1.

6. Engel J, Bächinger HP. Structure, stability and folding of the collagen triple helix. Top Curr Chem. 2005;247:7-33.

7. Brodsky B, Persikov AV. Molecular structure of the collagen triple helix. Adv in Protein Chem. 2005:70:301-39.

8. Usha R, Ramasami T. Influence of hydrogen bond, hydrophobic and electrovalent salt linkages on the transition temperature, enthalpy and activation energy in rat tail tendon (RTT) collagen fibre. Thermochim Acta. 1999;338:17-25.

9. Brodsky B, Ramshaw JAM. The collagen triple-helix structure. Matrix Biol. 1997:15:545-54.

10. Lee $\mathrm{CH}$, Singla A, Lee Y. Biomedical applications of collagen. Int J Pharm. 2001;221:1-22

11. Kielty CM, Grant ME. In: Royce PM, Steinmann B, editors. The collagen family: structure, assembly, and organization in the extracellular matrix Connective tissue and its heritable disorders: molecular, genetic, and medical aspects, second edition. Hoboken: Wiley; 2003.

12. Yoon D, Cho YS, Joo SY, Seo C. A clinical trial with a novel collagen dermal substitute for wound healing in burn patients. Biomater Sci. 2020. https:// doi.org/10.1039/c9bm01209e.

13. Chen LJ, Bao B, Wang NP, Xie J, Wu WH. Oral administration of shark Type II collagen suppresses Complete Freund's Adjuvant-induced rheumatoid arthritis in rats. Pharmaceuticals. 2012;5:339-52.

14. Chen XF, Zhou LL, Xu HZ, Yamamoto M, Shinoda M, Tada I, Minami S, Urayama K, Yamane $H$. The structure and properties of natural sheep casing and artificial films prepared from natural collagen with various crosslinking treatments. Int J Biol Macromol. 2019;135:959-68.

15. Li GY, Fukunaga S, Takenouchi K, Nakamura F. Comparative study of the physiological properties of collagen, gelatin and collagen hydrolysate as cosmetic materials. Int J Cosmet Sci. 2005;27:101-6.

16. Li Y, Liu WT, Du ZL, Li GY. Comparison of dynamic denaturation temperature of collagen with its static denaturation temperature and the configuration characteristics in collagen denaturation processes. Thermochim Acta. 2008;469(1-2):71-6.

17. Burjanadze TV, Veis A. A thermodynamic analysis of the contribution of hydroxyproline to the structural stability of the collagen triple helix. Connect Tissue Res. 1997:36(4):347-65.

18. Zhang ZK, Li GY, Shi B. Physicochemical properties of collagen, gelatin and collagen hydrolysate derived from bovine limed split wastes. J Soc Leather Tech Chem. 2006:90:23-8.

19. Sadowska M, Koiodziejska I, Niecikowska C. Isolation of collagen from the skins of Baltic cod (Gadus morhua). Food Chem. 2003;81(2):257-62.

20. Skierka E, Sadowska M. The influence of different acids and pepsin on the extractability of collagen from the skin of Baltic cod (Gadus morhua). Food Chem. 2007;105(3):1302-6.

21. Takahashi S, Geenen D, Nieves E. Collagenase degrades collagen in vivo in the ischemic heart. Biochim Biophys Acta. 1999;1428:251-9.

22. Zhang ZQ, Zhang YH, An Q, Xu RR, Li H, Wang EB. Study on immunogenicity of type I atelocollagen. Chin J Tissue Eng Res. 2019;23(22): 3542-8

23. Veeruraj A, Arumugam M, Balasubramanian T. Isolation and characterization of thermostable collagen from the marine eel-fish (Evenchelys macrura). Process Biochem. 2013:48(10):1592-602.

24. Yu D, Chi CF, Wang B, Ding GF, Li ZR. Characterization of acid-and pepsinsoluble collagens from spines and skulls of skipjack tuna (Katsuwonus pelamis). Chin J Nat Med. 2014;12(9):712-20.
25. Li ZR, Wang B, Chi CF, Zhang QH, Gong YD, Tang JJ, Luo HY, Ding GF. Isolation and characterization of acid soluble collagens and pepsin soluble collagens from the skin and bone of Spanish mackerel (Scomberomorous niphonius). Food Hydrocoll. 2013;31(1):103-13.

26. Portier RJ, Moody MW, Ogawa M. Biochemical properties of black drum and sheepshead seabream skin collagen. J Agric Food Chem. 2003:51(27):8088-92.

27. Wang J, Pei XL, Liu HY, Zhou D. Extraction and characterization of acidsoluble and pepsin-soluble collagen from skin of loach ( Misgurnus anguillicaudatus ). Int J Biol Macromol. 2017. https://doi.org/10.1016/j. ijbiomac.2017.08.046

28. Gao LL, Wang ZY, Li Z, Zhang CX, Zhang DQ. The characterization of acid and pepsin soluble collagen from ovine bones (Ujumuqin sheep). J Integr Agric. 2018;17(3):704-11.

29. Chen Y, Ye R, Wang Y. Aci-soluble and pepsin-soluble collagens from grass carp (Ctenopharyngodon idella) skin: a comparative study on physicochemical properties. Int J Food Sci Technol. 2015;50(1):186-93.

30. Sun LL, Hou H, Li BF, Zhang Y. Characterization of acid- and pepsin-soluble collagen extracted from the skin of Nile tilapia (Oreochromis niloticus). Int J Biol Macromol. 2017:99:8-14.

31. Matmaroh K, Benjakul S, Prodpran T, Encarnacion AB, Kishimura H. Characteristics of acid soluble collagen and pepsin soluble collagen from scale of spotted golden goatfish (Parupeneus heptacanthus). Food Chem. 2011;129(3):1179-86

32. Zhang M, Liu WT, Li GY. Isolation and characterisation of collagens from the skin of largefin longbarbel catfish (Mystus macropterus). Food Chem. 2009; 115(3):826-31.

33. Wang L, An X, Xin Z, Zhao L, Hu Q. Isolation and characterization of collagen from the skin of deep-sea redfish (Sebastes mentella). J Food Sci. 2007;72(8):E450-5.

34. Zhang JJ, Duan R. Characterisation of acid-soluble and pepsin-solubilised collagen from frog (Rana nigromaculata) skin. Int J Biol Macromol. 2017;101: 638-42.

35. Heu MS, Lee JH, Kim HJ, Jee SJ, Lee JS, Jeon YJ, Shahidi F, Kim JS Characterization of acid- and pepsin-soluble collagens from flatfish skin. Food Sci Biotechnol. 2010;19(1):27-33.

36. Kittiphattanabawon P, Benjakul S, Visessanguan W, Shahidi F. Isolation and properties of acid-and pepsin-soluble collagen from the skin of blacktip shark (Carcharhinus limbatus). Eur Food Res Technol. 2010;230(3):475-83.

37. Singh P, Benjakul S, Maqsood S, Kishimura H. Isolation and characterisation of collagen extracted from the skin of striped catfish (Pangasianodon hypophthalmus). Food Chem. 2011;124(1):97-105.

38. Kozlowska J, Sionkowska A, Skopinska-Wisniewska J, Piechowicz K. Northern pike (Esox lucius) collagen: extraction, characterization and potential application. Int J Biol Macromol. 2015;81:220-7.

39. Sato K, Ebihara T, Adachi E, Kawashima S, Hattori S, Irie S. Possible involvement of aminotelopeptide in self-assembly and thermal stability of collagen I as revealed by its removal with proteases. J Biol Chem. 2000; 275(33):25870-5

40. Walton RS, Brand DD, Czernuszka JT. Influence of telopeptides, fibrils and crosslinking on physicochemical properties of type I collagen films. J Mater Sci Mater Med. 2010;21(2):451-61.

41. Woodley DT, Yamauchi M, Wynn KC, Mechanic G, Briggaman RA. Collagen telopeptides (cross-linking sites) play a role in collagen gel lattice contraction. J Invest Dermatol. 1991;97(3):580-5.

42. Piez KA, Trus BL. Microfibrillar structure and packing of collagen: hydrophobic interactions. J Mol Biol. 1977;110(4):701-4.

43. Bowes JH, Kenten RH. The effect of alkalis on collagen. Biochem J. 1948; 43(3):365-72.

44. Courts A. Structural changes in collagen. The action of alkalis and acids in the conversion of collagen into eucollagen. Biochem J. 1960;74(2):238-47.

45. Kuehn K, Zimmer E, Waykole P, Fietzek P. The effect of alkali on collagen. The change in the charge pattern of the tropocollagen molecule and splitting of intra- and intermoleculer compounds. Hoppe Seylers Z Physiol Chem. 1963:333:209-17.

46. Kemp GD, Tristram GR. The preparation of an alkali-soluble collagen from demineralized bone. Biochem J. 1971;124(5):915-9.

47. Hattori S, Adachi E, Ebihara T, Shirai T, Someki I, Irie S. Alkali-treated collagen retained the triple helical conformation and the ligand activity for the cell adhesion via a2 $\beta 1$ integrin. J Biochem. 1999;125:676-84.

48. Suzuki Y, Someki I, Adachi E, Irie S, Hattori S. Interaction of collagen molecules from the aspect of fibril formation: acid-soluble, alkali-treated, 
and MMP1-digested fragments of type I collagen. Jpn Biochem Soc. 1999; 128:54-67.

49. Zhao S, Zhang M, Li GY, Liu WT. Preparation and characterization of alkalisoluble collagen from pigskin shavings. J Am Leather Chem Assoc. 2009; 104:344-51.

50. Jayasooriya SD, Bhandari BR, Torley P, D'Arcy BR. Effect of high power ultrasonic waves on properties of meat: a review. Int J Food Prop. 2004;7(2): 301-19.

51. Kruus $P, O^{\prime} N$ eill M, Robertson D. Ultrasonic initiation of polymerization. Ultrasonics. 1990;28:304-9.

52. Akram $\mathrm{A}$, Zhang $\mathrm{CH}$. Effect of ultrasonication on the yield, functional and physicochemical characteristics of collagen-II from chicken sternal cartilage. Food Chem. 2019. https://doi.org/10.1016/j.foodchem.2019.125544.

53. Qu Y, Su HY, Liu WT, Li GY. Extraction of collagen from bovine hide assisted by ultrasonic. Leather Sci Eng. 2018;28(2):05-9.

54. Ran $X G$, Wang LY. Use of ultrasonic and pepsin treatment in tandem for collagen extraction from meat industry by-products. J Sci Food Agric. 2014; 94(3):585-90.

55. Li DF, Mu CD, Cai SM, Lin W. Ultrasonic irradiation in the enzymatic extraction of collagen. Ultrason Sonochem. 2009;16(5):605-9.

56. Zou Y, Xu PP, Li PP, Cai PP, Zhang MH, Sun ZL, Sun C, Xu WM, Wang DY Effect of ultrasonic pre-treatment on the characterization and properties of collagen extracted from soft-shelled turtle (Pelodiscus sinensis). Food Sci Technol. 2017;82:72-81.

57. Jung SK, Kim YH, Kim YE, Song KM, Lee NH. Development of industrial ultrasonic system for mass production of collagen and biochemical characteristics of extracted collagen. Food Bioprod Process. 2018. https:// doi.org/10.1016/j.fbp.2018.04.001.

58. Kim HK, Kim YH, Kim YJ, Park HJ, Lee NH. Effects of ultrasonic treatment on collagen extraction from skins of the sea bass Lateolabrax japonicus. Fish Sci. 2012;78(2):485-90.

59. Kim HK, Kim YH, Park HJ, Lee NH. Application of ultrasonic treatment to extraction of collagen from the skins of sea bass Lateolabrax japonicus. Fish Sci. 2013;79(5):849-56.

60. Huang KM, Yang XQ. New progress in the study of non-thermal effects in microwave accelerated chemical reactions. Prog Nat Sci. 2006;16(3):273-9.

61. Li YW, Li HJ. Optimization of microwave-assisted extraction process for collagen from pigskin. Food Sci. 2012;33(6):11-4.

62. Cheng YL, Wu JC, Zhang JW, Chen WY. A novel collagen extraction method ased on microwave irradiation. Dresden: XXXV IULTCS Congress; 2019.

63. Li DF, Mu CD, Zhang $Q$, Zhou YL, Lin W. Effects of microwave irradiation on collagen denaturation. J Food Biochem. 2010;34(6):1319-31.

64. Jenness DD, Sprecher C, Johnson WC. Circular dichroism of collagen, gelatin, and poly (proline) II in the vacuum ultraviole. Biopolymers. 1976; 15(3):513-21.

65. Li D, Yang W, Li GY. Extraction of native collagen from limed bovine split wastes through improved pretreatment methods. J Chem Technol Biotechnol. 2008;83:1041-8.

66. Xu SC, Yang H, Shen LR, Li GY. Purity and yield of collagen extracted from Southern catfish (Silurus meridionalis Chen) skin through improved pretreatment methods. Int J Food Prop. 2017;20:141-53.

67. Earle M, Seddon K. Ionic liquids, green solvents for the future. Pure Appl Chem. 2000;72(7):1391-8.

68. Vijayaraghavan R, Vedaraman N, Muralidharan C, Mandal AB, MacFarlane DR. Aqueous ionic liquid solutions as alternatives for sulphide-free leather processing. Green Chem. 2015;17:1001-7.

69. Jayakumar GC, Mehta A, Rao JR, Fathima NN. Ionic liquids: new age materials for eco-friendly leather processing. RSC Adv. 2015;5:31998-2005.

70. Alla JP, Rao JR, Fathima NN. Integrated depilation and fiber opening using aqueous solution of ionic liquid for leather processing. ACS Sustain Chem Eng. 2017;5:8610-8.

71. Liu SC, Liu WT, Li GY. Effect of ionic liquids pretreatmen on the extaction of collagen from calf skin. J Am Leather Chem. 2019;114:391-9.

72. Rodríguez MIA, Barroso LGR, Sánchez ML. Collagen: a review on its sources and potential cosmetic applications. J Cosmet Dermatol. 2017;10:1-7.

73. Li GY, Liu WT. Collagen chemistry. 1st ed. China: China Light Industry Press; 2013.

74. Joy DP, Kumar KK, Kumar SKS. Collagen from squid and its bioliogical activity. Int J Curr Pharm Res. 2017;9(3):24-6.

75. Kotler ED, Marshall WS, Gareta EG. Sources of collagen for biomaterials in skin wound healing. Bioengineering. 2019. https://doi.org/10.3390/ bioengineering6030056.
76. Burianadze TV. New analysis of the phylogenetic change of collagen thermostability. Biopolymers. 2000;53:523-8.

77. Ikoma T, Kobayashi H, Tanaka J, Walsh D, Mann S. Physical properties of type I collagen extracted from fish scales of Pagrus major and Oreochromis niloticas. Biol Macromol. 2003;32:199-204.

78. Burjanadze TV. Hydroxyproline content and location in relation to collagen thermal stability. Pept Sci. 1979;18(4):931-8.

79. Lodhi G, Kim YS, Kim EK, Hwan JW, Won HS, Kim W, Moon SH, Jeon BT, Park PJ. Isolation and characterisation of acid- and pepsin-soluble collagen from the skin of Cervus korean TEMMINCK var. mantchuricus Swinhoe. Anim Prod Sci. 2018;58(3):585-94.

80. Zhang FX, Wang AN, Li ZH, He SW, Shao LJ. Preparation and characterisation of collagen from Freshwater fish scales. Food Nutr Sci. 2011, 2:818-23.

81. Liu WT, Li GY, Miao YQ, Wu XH. Peparation and characterization of pepsinsolubilized type I collagen from the scales of snakhead (ophiocephalus argus). Food Biochem. 2009;33(1):20-37.

82. Li H, Liu BL, Gao LZ, Chen HL. Studies on bullfrog skin collagen. Food Chem. 2004;84(1):65-9.

83. Ahmad M, Benjakul S. Extraction and characterisation of pepsin-solubilised collagen from the skin of unicorn leatherjacket (Aluterus monocerous). Food Chem. 2010;120(3):817-24.

84. Zelechowska E, Sadowska M, Turk M. Isolation and some properties of collagen from the backbone of Baltic cod (Gadus morhua). Food Hydrocoll. 2010;24(4):325-9.

85. Wang SS, Sun XQ, Zhou DQ. Physicochemical characteristics and fibrilforming properties of collagen from paddlefish ( polyodon spathula ) and globefish (Fugu flavidus) skin byproducts. Food Sci Technol. 2017;37(2):17683.

86. Barzideh Z, Latiff AA, Gan CY, Benjakul S, Karim AA. Isolation and characterisation of collagen from the ribbon Jellyfish (Chrysaora sp.). Food Sci Technol. 2013. https://doi.org/10.1111/ijfs. 12464.

87. Wu JL, Guo XB, Liu H, Chen L. Isolation and comparative study on the characterization of guanidine hydrochloride soluble collagen and pepsin soluble collagen from the body of surf clam shell (Coelomactra antiquata). Foods. 2019. https://doi.org/10.3390/foods8010011.

88. Song WK, Liu D, Li BF, Hou H. Physicochemical and biocompatibility properties of Type I collagen from the skin of Nile Tilapia (Oreochromis niloticus) for biomedical applications. Mar Drugs. 2019. https://doi.org/10. 3390/md17030137.

89. Zhong $\mathrm{M}$, Chen $\mathrm{T}$, $\mathrm{Hu} \mathrm{CQ}$, Ren $\mathrm{CH}$. Isolation and characterization of collagen from the body wall of sea cucumber stichopus monotuberculatus. Food Chem. 2015. https://doi.org/10.1111/1750-3841.12826.

90. Nagai T, Araki Y, Suzuki N. Collagen of the skin of ocellate puffer fish (Takifugu rubripes). Food Chem. 2002;78(2):173-7.

91. Tziveleka LA, loannou E, Tsiourvas D, Berillis P, Foufa E, Roussis V. Collagen from the marine sponges Axinella cannabina and Suberites carnosus: isolation and morphological, biochemical, and biophysical bharacterization. Mar Drugs. 2017. https://doi.org/10.3390/md15060152.

92. Zhang Y, Liu WT, Li GY, Shi B, Miao YQ, Wu XH. Isolation and partial characterization of pepsin-soluble collagen from the skin of grass carp (Ctenopharyngodon idella). Food Chem. 2007;103:906-12.

93. Tan CC, Karim AA, Latiff AA, Gan CY, Ghazali FC. Extraction and characterization of pepsin-solubilized collagen from the body wall of crown-of-thorns Starfish (Acanthaster planci). Int Food Res. 2013;20(6):3013-20.

94. Rigby BJ. Amino-acid composition and thermal stability of the skin collagen of the Antarctic Ice-fish. Nature. 1968;219:166-7.

95. Veeruraj A, Arumugam M, Ajithkumar T, Balasubramanian T. Isolation and characterization of collagen from the outer skin of squid (Doryteuthis singhalensis). Food Hydrocoll. 2015;43:708-16.

96. Muralidharan N, Shakia RJ, Sukumar D, Jeyasekaran G. Skin, bone and muscle collagen extraction from the trash fish, leather jacket (Odonus niger) and their characterization. Food Sci Technol. 2013;50(6):1106-13.

97. Kim JS, Park JW. Characterization of acid-soluble collagen from pacific whiting surimi processing byproducts. Food Chem Technol. 2004;69(8):637-42.

98. Gaill F, Mann K, Wiedemann H, Engel J, Timpl R. Structural comparison of cuticle and interstitial collagens from annelids living in shallow sea-water and at deep-sea hydrothermal vents. J Mol Biol. 1995;246(2):284-94.

99. Duan R, Konno K, Wang SJ. Different thermostability of collagens from scale of carp (cyprius carpio) in winter and summer. Food Biochem. 2010;34: $1275-87$. 
100. Pan BS, Chen HE, Sung WC. Molecular and thermal characteristics of acidsoluble collagen from orbicular batfish: effects of deep-sea water culturing Food Prop. 2018;21(1):1080-90.

101. Berg RA, Prockop DJ. The thermal transition of a non-hydroxylated from of collagen, evidence for a role for hydroxyproline in stabilizing the triple-helix of collagen. Biochem Biophys Res Commun. 1973;52(1):116-20.

102. Rosenbloom J, Harsch M. Hydroxyproline content determines the denaturation on temperature of chkick tendon collagen. Biochem Biophys. 1973;158:478-84.

103. Gustavson KH. The function of hydroxyproline in collagens. Nature. 1955; 175(4445):70-4.

104. Miles CA, Knott L, Sumner IG, Bailey AJ. Differences between the thermal stabilities of the three triple-helical domains of type IX collagen. J Mol Biol. 1998;277(1):135-44.

105. Miles CA, Bailey AJ. Thermally labile domains in the collagen molecule. Micron. 2001;32(3):325-32.

106. Josse J, Harrington WF. Role of pyrrolidine residues in the structure and stabilization of collagen. J Mol Biol. 1964;9(2):269-87.

107. Gaill F. Aspects of life development at deep sea hydrothermal vents. FASEB J. 1993;7(6):558-65.

108. Engel J, Kurtz J, Katchalski E, Berger A. Polymers of tripeptides as collagen models: II. Conformational changes of poly (L-prolyl-glycyl-L-prolyl) in solution. J Mol Biol. 1966;17(1):225-72.

109. Rao NV, Harrington WF. Relationship between the positioning of pyrrolidine residues and the stability of collagen. J Mol Biol. 1966;21:577-81.

110. Nagarajan V, Kamitori S, Okuyama K. Structure analysis of a collagen-model peptide with a (Pro-Hyp-Gly) sequence repeat. J Biochem. 1999;125(2):310-

111. Kramer RZ, Bella J, Mayville P, Brodsky B, Berman H. Sequence dependent conformational variations of collagen triplehelical structure. Nat Struct Biol. 1999;6(5):454-7.

112. Shah NK, Ramshaw JAM, Kirkpatrick A, Shah C, Brodsky B. A host-guest set of triple-helical peptides: stability of Gly-X-Y triplets containing common nonpolar residues. Biochemistry. 1996;35(32):10262-8.

113. Persikov AV, Ramshaw JAM, Brodsky B. Collagen model peptides: Sequence dependence of triple-helix stability. Biopolymers. 2000;55(6):436-50.

114. Inouye K, Sakakibara S, Prockop DJ. Effects of the stereo-configuration of the hydroxyl group in 4-hydroxyproline on the triple-helical structures formed by homogenous peptides resembling collagen. Biochim Biophys Acta. 1976; 420(1):133-41.

115. Friedman L, Higgin JJ, Moulder G, Barstead R, Raines RT, Kimble J. Prolyl 4hydroxylase is required for viability and morphogenesis in Caenorhabditis elegans. Proc Natl Acad Sci U S A. 2000;97(9):4736-41.

116. Bella J, Eaton M, Brodsky B, Berman HM. Crystal and molecular structure of a

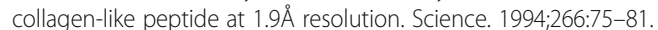

117. Bella J, Brodsky B, Berman HM. Hydration structure of a collagen peptide Structure. 1995:3:893-906.

118. Persikov AV, Ramshaw AM, Kirkpatrick A, Brodsky B. Triple-helix propensity of hydroxyproline and fluoroproline: comparison of host-guest and repeating tripeptide models. J Am Chem Soc. 2003;125:11500-1.

119. Holmgren SK, Taylor KM, Bretscher LE, Raines RT. Code for collagen's stability deciphered. Nature. 1998;392(6677):666-7.

120. Holmgren SK, Bretscher LE, Taylor KM, Raines RT. A hyperstable collagen mimic. Chem Biol (London). 1999;6(2):63-70.

121. Goldstein A, Adams E. Glycylhydroxyprolyl sequences in earthworm cuticle collagen: glycylhydroxyprolylserine. J Biol Chem. 1970;245(20):5478-83.

122. Kefalides NA. Structure and biosynthesis of basement membranes. Int Rev Connect Tissue Res. 1973;6:63-104.

123. Mizuno K, Hayashi T, Peyton DH, Bächinger HP. Hydroxylation-induced stabilization of the collagen triple helix. J Biol Chem. 2004;279(36):38072-8.

124. Improta R, Berisio R, Vitagliano L. Contribution of dipole-dipole interactions to the stability of the collagen triple helix. Protein Sci. 2008;17(5):955-61.

125. Inouye K, Kobayashi Y, Kyogoku Y, Kishida Y, Sakakibara S, Prockop DJ. Synthesis and physical properties of (hydroxyproline-proline-glycine) ${ }_{10}$. Hydroxyproline in the X-position decreases the melting temperature of the collagen triple helix. Arch Biochem Biophys. 1982;219:198-203.

126. Vitagliano L, Berisio R, Mazzarella L, Zagari A. Structural bases of collagen stabilization induced by proline hydroxylation. Biopolymers. 2001;58(5):459-64.

127. Berisio R, Granata V, Vitagliano L, Zagari A. Imino acids and collagen triple helix stability: characterization of collagen-like polypeptides containing HypHyp-Gly sequence repeats. J Am Chem Soc. 2004;126(37):11402-3.
128. Mann K, Mechling DE, Bächiger HP, Eckerskorn C, Gaill F, Timpl R. Glycosylated threonine but not 4-hydroxyproline dominates the triple helix stabilizing positions in the sequence of a hydrothermal vent worm cuticle collagen. J Mol Biol. 1996;261(2):255-66.

129. Bann JG, Peyton DH, Bächinger HP. Sweet is stable: glycosylation stabilizes collagen. FEBS Lett. 2000:473(2):237-40.

130. Bann JG, Bächinger HP, Peyton DH. Role of carbohydrate in stabilizing the triple-helix in a model for a deep-sea hydrothermal vent worm collagen. Biochemistry. 2003;42(14):4042-8.

131. Xu SC, Gu M, Wu K, Li GY. Unraveling the role of hydroxyproline in maintaining the thermal stability of the collagen triple helix structure using simulation. Phys Chem. 2019;123:7754-63.

132. Liu WT, Li GY. Non-isothermal kinetic analysis of the thermal denaturation of type I collagen in solution using isoconversional and multivariate non-linear regression methods. Polym Degrad Stabil. 2010;95:2233-40.

133. Ding CC, Zhang M, Wu K, Li GY. The response of collagen molecules in acid solution to temperature. Polymer. 2014;55:5751-9.

134. Wu K, Liu WT, Li GY. The aggregation behavior of native collagen in dilute solution studied by intrinsic fluorescence and external probing. Spectrochim Acta A Mol Biomol Spectrosc. 2013;102:186-93.

135. Bella J. Collagen structure: new tricks from a very old dog. Biochemistry. 2016;473:1001-250.

136. Cassel JM. Collagen aggregation phenomena. Biopolymers. 1966;4(9):98997.

137. Liu WT, Tian ZH, Li CH, Li GY. Thermal denaturation of fish collagen in solution: a calorimetric and kinetic analysis. Thermochim Acta. 2014;581(6): 32-40.

138. Yang H, Xu SC, Shen LR, Liu WT, Li GY. Changes in aggregation behavior of collagen molecules in solutionwith varying concentrations of acetic acid. Biol Macromol. 2016:92:581-6.

139. Hofmeister F. On the understanding of the effects of salts. Arch Exp Pathol Pharmakol. 1888;24:247-60.

140. Luescher M. Effect of hydration upon the thermal stablility of tropocollagen and its sependence on the presence of neutral salts. Biopolymers. 1974;13: 2489-530.

141. Combariza JE, Kestner NR, Jortner J. Energy-structure relationships for microscopic solvation of anions inwater clusters. J Chem Phys. 1994;100: 2851-64.

142. Grossfield A, Ren P, Ponder JW. Ion solvation thermodynamics from simulation with a polarizable force field. J Am Chem Soc. 2003;125:1567182.

143. Komsa-Penkova R, Koynova R, Tenchov BG, et al. Thermal stability of calf skin collagen type I in salt solutions. Biochim Biophys Acta. 1996;1297:17181.

144. Goindi S, Kaur R, Kaur R. An ionic liquid-in-water microemulsion as a potential carrier for topical delivery of poorly water soluble drug: development, ex-vivo, and in-vivo, evaluation. Int J Pharm. 2015:495(2):91323.

145. Hayes R, Warr GG, Atkin R. Structure and nanostructure in ionic liquids. Chem Rev. 2015;115(13):6357-642.

146. Tarannum A, Muvva C, Mehta A, Rao RJ, Fathima NN. Role of preferential ions of ammonium ionic liquid in destabilization of collagen. J Phys Chem B. 2016. https://doi.org/10.1021/acs.jpcb.6b02723.

147. Tarannum A, Adams A, Blumich B, Fathima NN. Impact of ionic liquids on the structure and dynamics of collagen. J Phys Chem B. 2017:122(3):1060-5.

148. Mehta A, Raghava RJ, Fathima NN. Electrostatic forces mediated by choline dihydrogen phosphate stabilize collagen. J Phys Chem B. 2015;119(40): 12816-27.

149. Yang H, Li Q, Liu SC, Li GY. Acetic acid/1-ethyl-3-methylimidazolium acetate as a biphasic solvent system for altering the aggregation behavior of collagen molecules. J Mol Liquids. 2018;262:78-85.

150. Liu SC, Li Q, Li GY. Investigation of the solubility and dispersion degree of calf skin collagen in ionic liquids. J Leather Sci Eng. 2019. https://doi.org/10. 1186/s42825-019-0013-9.

151. Zhai ZW, Wang HB, Wei BM, Yu PW, Xu CZ, He L, Zhang JT, Xu YL. Effect of ionic liquids on the fibril-formation and gel properties of grass carp (Ctenopharyngodon idellus) skin collagen. Macromol Res. 2018;26(7):609-15.

152. Tanford C. The hydrophobic effect: formation of micelles and biological membranes 2nd ed. New York: Wiley; 1980.

153. Penkova R, Goshev I, Gorinstein S, Nedkov P. Stability of collagen during denaturation. J Protein Chem. 1999;18(4):397-401. 
154. Penkova R, Goshev I, Gorinstein S, Nedkov P. Stabilizing effect of glycerol on collagen type I isolated from different species. Food Chem. 1999;66(4):483-7.

155. Na GC. Interaction of calf skin collagen with glycerol: linked function analysis. Biochemistry. 1986;25(5):967-73.

156. Li JH, Li GY. The thermal behavior of collagen in solution: effect of glycerol and 2-propanol. Int J Biol Macromol. 2011:48(2):364-8.

157. Li JH, Liu WT, Li GY. The effect of glycerol and 2-propanol on the molecular aggregation of collagen in solution. Int J Biol Macromol. 2015;72:1097-103.

158. Usha R, Ramasami T. Role of aliphatic alcohols on the stability of rat-tail tendon (RTT) collagen fiber. J Polym Sci B Polym Phys. 1999;37(13):1397405.

159. Usha R, Ramasami T. The effects of urea and n-propanol on collagen denaturation: using DSC, circular dicroism and viscosity. Thermochim Acta. 2004;409(2):201-6.

160. Nezu T, Morikawa T, Sasaki K, Saitoh S, Taira M, Terada Y, Araki Y. New index for the stability of a type I collagen affected by hydrophobic environment. Dent Mater J. 2007;26(3):373-81.

161. Shanmugam G, Reddy SMM, Madhan B, Rao JR. Method of addition of acetonitrile influences the structure and stability of collagen. Process Biochem. 2014:49(2):210-6.

162. Gopinath A, Reddy SM, Madhan B, Shanmguam G, Rao JR. Effect of aqueous ethanol on the triple helical structure of collagen. Eur Biophys J. 2014;43(12): 643-52.

163. Usha R, Maheshwari R, Dhathathreyan A, Ramasami T. Structural influence of mono and polyhydric alcohols on the stabilization of collagen. Colloids Surf B Biointerfaces. 2006;48(2):101-5.

164. Hart GJ, Russell AE, Cooper DR. The effects of certain glycols, substituted glycols and related organic solvents on the thermal stability of soluble collagen. Biochem J. 1971;125(2):599-604.

165. Lewandowska K, Sionkowska A, Grabska S, Kaczmarek B, Michalska M. The miscibility of collagen/hyaluronic acid/chitosan blends investigated in dilute solutions and solids. J Mol Liquids. 2016;220:726-30.

166. Tian HL, Li CH, Liu WT, Li JH, Li GY. The influence of chondroitin 4-sulfate on the reconstitution of collagen fibrils in vitro. Colloids Surf B Biointerfaces. 2013;105:259-66

167. Zhao S, Lu W, Li GY. Reserch on properties of collagen/HA composite sponge. Leather Sci Eng. 2008;18(5):12-7.

168. Tian HL, Chen YH, Ding CC, Li GY. Interaction study in homogeneous collagen/chondroitin sulfate blends by two-dimensional infrared spectroscopy. Carbohydr Polym. 2012;89(2):542-50.

169. Tan QT, Tian ZH, Li GY. Specific interaction study in collagen/hyaluronic acid blends by two-dimensional infrared correlation spectroscopy. Spectrosc Spect Anal. 2011;31(4):970-4.

170. Ding CC, Zhang M, Li GY. Preparation and characterization of collagen/ hydroxypropyl methylcellulose (HPMC) blend film. Carbohydrate Polymers. 2015;119:194-201

171. Ding CC, Zhang M, Tian HL, Li GY. Effect of hydroxypropyl methylcellulose on collagen fibril formation in vitro. Int J Biol Macromol. 2013;52:319-26.

172. Ding CC, Tian HL, Li GY. Specific interaction in collagen/hydroxypropyl methylcellulose blends studied by viscometry and two-dimensional infrared correlation spectroscopy. J Funct Mater. 2012:43(8):992-6.

173. Li CH, Tian HL, Duan L, Tian ZH, Li GY. Characterization of acylated pepsinsolubilized collagen with better surface activity. Int J Biol Macromol. 2013; 57:92-8

174. Zhang M, Ding CC, Yaang JH, Lin S, Chen LH, Huang LL. Study of interaction between water-soluble collagen and carboxymethyl cellulose in neutral aqueous solution. Carbohydr Polym. 2016;137:410-7.

175. Fu Q, Li GY. Study of improving properties of collagen membrane by blending chitosan and collagen. China Leather. 2007:36(5):22-5.

176. Sionkowska A, Wisniewski M, Skopinska S, Kennedy CJ, Wess TJ. Molecular interactions in collagen and chitosan blends. Biomaterials. 2004:25:795-801.

177. Mitra T, Sailakshmi G, Gnanamani A, Raja STK, Thiruselvi T, Gowri VM, Selvaraj NV, Ramesh G, Mandal AB. Preparation and characterization of a thermostable and biodegradable biopolymers using natural cross-linker. Int J Biol Macromol. 2011;48(2):276-85

178. Lai GL, Du ZL, Li GY. The rheological behavior of collagen dispersion/poly (vinyl alcohol) blends. Korea Aust Rheol J. 2007;19(2):81-8.

179. Sarti B, Scandola M. Viscoelastic and thermal properties of collagen/poly (vinyl alcohol) blends. Biomaterials. 1995;16(10):785-92.

180. Sionkowska A. Interaction of collagen and poly (vinyl pyrrolidone) in blends. Eur Polym J. 2003;39(11):2135-40.
181. Sionkowska A, PłAnecka A, KozłOwska J, Skopińska-Wiśniewska J. Collagen fibril formation in poly (vinyl alcohol) and poly (vinyl pyrrolidone) films. J Mol Liquids. 2009;144(1):71-4.

182. Xue $Y$, Liu $X H$, Ju HY, Dan NH, Dan WH. Effect on structure and performace of type I collagen after modified by polyethylene glycol. China Leather. 2013:42(33):10-4.

183. Jose MV, Thomas V, Dean DR, Nyairo E. Fabrication and characterization of aligned nanofibrous PLGA/Collagen blends as bone tissue scaffolds. Polymer. 2009;50(15):3778-85.

184. Gorham SD, Light ND, Diamond AM, Willins MJ, Bailey AJ, Wess TJ, Leslie NJ. Effect of chemical modifications on the susceptibility of collagen to proteolysis. II. Dehydrothermal crosslinking. Int J Biol Macromol. 1992;14(3): 129-38.

185. Weadock KS, Miller EJ, Keuffel EL, Dunn MG. Effect of physical crosslinking methods on collagen-fiber durability in proteolytic solutions. J Biomed Mater Res. 1996:32(2):221-6.

186. Hu Y, Liu L, Gu ZP, Dan WH, Dan NH, Yu XX. Synergistic effect of carbodiimide and dehydrothermal crosslinking on acellular dermal matrix. Int J Biol Macromol. 2013:55:221-30.

187. Safandowska M, Pietrucha K. Effect of fish collagen modification on its thermal and rheological properties. Int J Biol Macromol. 2013;53:32-7.

188. Schroepfer M, Meyer M. DSC investigation of bovine hide collagen at varying degrees of crosslinking and humiditie. Int J Biol Macromol. 2017; 103:120-8.

189. Shen LR, Xu SC, Wu K, Li GY. Novel method for preparing of fish collagen gels with excellent physicochemical propertiess via the dehhydration of ethanol. Dresden: XXXV IULTCS Congress; 2019.

190. Sionkowska A, Kamińska A. Thermal helix-coil transition in UV irradiated collagen from rat tail tendon. Int J Biol Macromol. 1999;24(4):337-40.

191. Sionkowska A. Thermal denaturation of UV-irradiated wet rat tail tendon collagen. Int J Biol Macromol. 2005;35(3-4):145-9.

192. Metreveli NO, Namicheishvili LO, Dzhariashvili KK, Chikvaidze E, Mrevlishvili GM. A microcalorimetric and electron spin resonance study of the influence of UV radiation on collagen. Biophysics. 2006;51(1):29-32.

193. Hawkins CL, Davies MJ. Generation and propagation of radical reactions on proteins. Biochim Biophys Acta. 2001;1504(2):196-219.

194. Inoue N, Bessho M, Furuta M, Kojima T, Okuda S, Hara M. A novel collagen hydrogel cross-linked by gamma-ray irradiation in acidic $\mathrm{pH}$ conditions. J Biomater Sci Polym Ed. 2006;17(8):837-58.

195. Zhang XM, Xu L, Huang X, Wei S, Zhai M. Structural study and preliminary biological evaluation on the collagen hydrogel crosslinked by $\gamma$-irradiation. J Biomed Mater Res A. 2012;100A(11):2960-9.

196. Jiang B, Wu ZH, Zhao HC, Taang FY, Lu J, Wei QR, Zhang XD. Electron beam irradiation modification of collagen membrane. Biomaterials. 2006;27(1):1523.

197. Usha R, Ramasami T. Effect of crosslinking agents (basic chromium sulfate and formaldehyde) on the thermal and thermomechanical stability of rat tail tendon collagen fibre. Thermochim Acta. 2000;356(1-2):59-66.

198. Han B, Jaurequi J, Tang BW, Nimni ME. Proanthocyanidin: a natural crosslinking reagent for stabilizing collagen matrices. J Biomed Mater Res A. 2003:65(1):118-24

199. Onem E, Yorgancioglu A, Karavana HA, Yilmaz O. Comparison of different tanning agents on the stabilization of collagen via differential scanning calorimetry. J Therm Anal Calorim. 2017;129(1):615-22.

200. Kuroda D, Niinoi M. Design and mechanical proerites of new $\beta$ - type titanium alloys for implant materials. Mater Sci Eng. 1998;A243:244-9.

201. Liu F, Shen LR, Li GY. Cross-linking of collagen sponges with zicronium complex. China Leather. 2012;41(21):24-7.

202. He LR, Mu CD, Shi JB, Zhang Q, Shi B, Lin W. Modification of collagen with a natural cross-linker, procyanidin. Int J Biol Macromol. 2011;48:354-9.

203. Madban B, Subramanian V, Rao R, Nair BU, Ramasami T. Stabilization of collagen using plant polyphenol: role of catechin. Int J Biol Macromol. 2005; 3:47-53.

204. Zhang M, Li CH, Li GY. Dyeing properties of catechin on collagen membrane. China Leather. 2014;43(15):9-12.

205. Yang H, Shen LR, Bu HH, Li GY. Stable and biocompatible hydrogel composites based on collagen and dialdehyde carboxymethyl cellulose in a biphasic solvent system. Carbohydr Polym. 2019:222:114974.

206. Hwang YJ, Larsen J, Krasieva TB, Lyubovitsky JG. Effect of genipin crosslinking on the optical spectral properties and structures of collagen hydrogels. ACS Appl Mater Interfaces. 2011;3(7):2579-84. 
207. Sung HW, Hsu HL, Shih CC, Lin DS. Cross-linking characteristics of biological tissues fixed with monofunctional or multifunctional epoxy compounds. Biomaterials. 1996;17(14):1405-10.

208. Chen YH, Zhang M, Liu WT, Li GY. Properties of alkali-solubilized collagen solution crosslinked by N-hydroxysuccinimide activated adipic acid. Korea Aust Rheol J. 2011;23(1):41-8.

209. Grabarek Z, Gergely J. Zero-length crosslinking procedure with the use of active esters. Anal Biochem. 1990;185(1):131-5.

210. Petite H, Frei V, Huc A, Herbage D. Use of diphenylphosphorylazide for cross-linking collagen-based biornaterials. J Biomed Mater Res. 1994;28:15965.

211. Griffin M, Casadio R, Bergamini CM. Transglutaminases: nature's biological glues. Biochem J. 2002;368(2):377-96.

212. Olde Damink LHH, Dijkstra PJ, Van Luyn MJA, Van Wachem PB, Nieuwenhuis P, Feijen J. Glutaraldehide as a cross-linking agentfor collagen-based biomaterials. J Mater Sci Mater Med. 1995;6(8):460-72.

213. Tian ZH, Li CH, Duan L, Li GY. Physicochemical properties of collagen solutions cross-linked by glutaraldehyde. Connect Tissue Res. 2014;55(3): 239-47.

214. Tian ZH, Liu WT, Li GY. The microstructure and stability of collagen hydrogel cross-linked by glutaraldehyde. Polym Degrad Stabil. 2016;130:264-70.

215. Rousseau CF, Gagnieu CH. In vitro cytocompatibility of porcine type I atelocollagen crosslinked by oxidized glycogen. Biomaterials. 2002;23:150310.

216. Chen $Y N$, Dan NH, Huang YP, Yang CK, Dan WH, Liang YX. Insights into the interactions between collagen and a naturally derived crosslinker, oxidized chitosan oligosaccharide. J Appl Polym Sci. 2019. https://doi.org/10.1002/ app.48489.

217. Hu Y, Liu L, Gu ZP, Dan WH, Dan NH, Yu XX. Modification of collagen with a natural derived cross-linker, alginate dialdehyde. Carbohydr Polym. 2014;102: 324-32.

218. Pietrucha K, Safandowska M. Dialdehyde cellulose-crosslinked collagen and its physicochemical properties. Process Biochem. 2015;50(12):2105-11.

219. Tan H, Wu B, Li CP, Mu CD, Li HL, Lin W. Collagen cryogel cross-linked by naturally derived dialdehyde carboxymethyl cellulose. Carbohydr Polym. 2015;129:17-24.

220. Sung HW, Chang Y, Chiu CT, Chen CN, Liang HC. Crosslinking characteristics and mechanical properties of a bovine pericardium fixed with a naturally occurring crosslinking agent. J Biomed Mat Res. 1999;47(2):116-26.

221. Sung HW, Liang IL, Chen CN, Huang RN, Liang HF. Stability of a biological tissue fixed with a naturally occurring crosslinking agent (genipin). J Biomed Mater Res. 2001;55(4):538-46.

222. Zeeman R, Dijkstra PJ, van Wachem PB, van Luyn MJA, Hendriks M, Cahalan PT, Feijien J. Crosslinking and modification of dermal sheep collagen using 1,4-butanediol diglycidyl ether. J Biomed Mater Res. 1999;46(3):424-33.

223. Shen SH, Sung HW, Tu R, Hata C, Lin D, Noishiki Y, Quijano RC. Characterization of a polyepoxy compound fixed porcine heart valve bioprosthesis. J Appl Biomater. 1994;5(2):159-62.

224. Zhang M, Li GY. Partial characterization of fish skin collagen cross-linked by N-hydroxysuccinimide activated adipic acid. J Aquat Food Prod Technol. 2014;23(1):44-58.

225. Zhang M, Wu K, Li GY. Interactions of collagen molecules in the presence of N-hydroxysuccinimide activated adipic acid (NHS-AA) as a crosslinking agent. Int J Biol Macromol. 2011;49(4):847-54.

226. Shen LR, Tian ZH, Liu WT, Li GY. Influence on the physicochemical properties of fish collagen gels using self-assembly and simultaneous crosslinking with the N-hydroxysuccinimide adipic acid derivative. Connect Tissue Res. 2015. https://doi.org/10.3109/03008207.2015.1020941.

227. Duan L, Liu WT, Tian ZH, Li CH, Li GY. Properties of collagen gels crosslinked by N-hydroxysuccinimide activated adipic acid deriviate. Int J Biol Macromol. 2014;69:482-8.

228. Yang JH, Ding CC, Huang LL, Zhang M, Chen LH. The preparation of poly( $\left(\gamma^{-}\right.$ glutamic acid)-NHS ester as a natural cross-linking agent of collagen. Int J Biol Macromol. 2017;97:1-7

229. Zhang M, Yang JH, Ding CC, Huang LL, Chen LH. A novel strategy to fabricate water-soluble collagen using poly( $\gamma$-glutamic acid)-derivatives as dual-functional modifier. React Funct Polym. 2018;122:131-9.

230. Zhang M, Yang JH, Deng F, Guo CC, Yang QL, Wu H, Ni YH, Huang LL, Chen LH, Ding CC. Dual-functionalized hyaluronic acid as a facile modifier to prepare polyanionic collagen. Carbohydr Polym. 2019;215:358-65.
231. Old Damink LHH, Dijkstra PJ, van Luyn MJA. Cross-linking of dermal sheep collagen using a water-soluble carbodiimide. Biomaterials. 1996;17(8):76573.

232. Rault I, Frei V, Herbage D, Abdul-Malak N, Huc A. Evaluation of different chemical methods for cros-linking collagen gel, films and sponges. J Mater Sci Mater Med. 1996;7(4):215-21.

233. Folk JE. Transglutaminases. Ann Rev Biochem. 1980;49:517-31.

234. Chen RN, Ho HO, Sheu MT. Characterization of collagen matrices crosslinked using microbial transglutaminase. Biomaterials. 2005;26(20):4229-35.

235. Cheng S, Wang WH, Li Y, Gao GX, Zhang K, Zhou JY, Wu ZN. Cross-linking and film-forming properties of transglutaminase-modified collagen fibers tailored by denaturation temperature. Food Chem. 2019;271:527-35.

\section{Publisher's Note}

Springer Nature remains neutral with regard to jurisdictional claims in published maps and institutional affiliations.

\section{Submit your manuscript to a SpringerOpen ${ }^{\circ}$ journal and benefit from:}

- Convenient online submission

- Rigorous peer review

- Open access: articles freely available online

High visibility within the field

- Retaining the copyright to your article

Submit your next manuscript at $>$ springeropen.com 